Review

\title{
Nanoparticle Drug- and Gene-eluting Stents for the Prevention and Treatment of Coronary Restenosis
}

\author{
Rui-Xing Yin ${ }^{1 凶}$, De-Zhai Yang ${ }^{2}$ and Jin-Zhen $\mathrm{Wu}^{1}$ \\ 1. Department of Cardiology, Institute of Cardiovascular Diseases, the First Affiliated Hospital, Guangxi Medical University, Nanning, \\ Guangxi, People's Republic of China. \\ 2. Department of Molecular Biology, Medical Scientific Research Center, Guangxi Medical University, Nanning, Guangxi, People's Re- \\ public of China.
}

\begin{abstract}
$\square$ Corresponding author: Rui-Xing Yin, Department of Cardiology, Institute of Cardiovascular Diseases, the First Affiliated Hospital, Guangxi Medical University, 22 Shuangyong Road, Nanning 530021, Guangxi, People's Republic of China. Telephone: (+86) 771-5326125; Fax: (+86) 771-5353342; E-mail: yinruixing@163.com.

(c) Ivyspring International Publisher. This is an open-access article distributed under the terms of the Creative Commons License (http://creativecommons.org/ licenses/by-nc-nd/3.0/). Reproduction is permitted for personal, noncommercial use, provided that the article is in whole, unmodified, and properly cited.
\end{abstract}

Received: 2013.07.20; Accepted: 2013.10.23; Published: 2014.01.08

\begin{abstract}
Percutaneous coronary intervention $(\mathrm{PCl})$ has become the most common revascularization procedure for coronary artery disease. The use of stents has reduced the rate of restenosis by preventing elastic recoil and negative remodeling. However, in-stent restenosis remains one of the major drawbacks of this procedure. Drug-eluting stents (DESs) have proven to be effective in reducing the risk of late restenosis, but the use of currently marketed DESs presents safety concerns, including the non-specificity of therapeutics, incomplete endothelialization leading to late thrombosis, the need for long-term anti-platelet agents, and local hypersensitivity to polymer delivery matrices. In addition, the current DESs lack the capacity for adjustment of the drug dose and release kinetics appropriate to the disease status of the treated vessel. The development of efficacious therapeutic strategies to prevent and inhibit restenosis after $\mathrm{PCl}$ is critical for the treatment of coronary artery disease. The administration of drugs using biodegradable polymer nanoparticles as carriers has generated immense interest due to their excellent biocompatibility and ability to facilitate prolonged drug release. Despite the potential benefits of nanoparticles as smart drug delivery and diagnostic systems, much research is still required to evaluate potential toxicity issues related to the chemical properties of nanoparticle materials, as well as to their size and shape. This review describes the molecular mechanism of coronary restenosis, the use of DESs, and progress in nanoparticle drug- or gene-eluting stents for the prevention and treatment of coronary restenosis.
\end{abstract}

Key words: Coronary artery disease, Stenosis, Restenosis, Stents, Nanoparticle.

\section{Introduction}

Coronary artery disease (CAD) is a major cause of morbidity and mortality in most industrialized nations and is of growing concern in developing countries [1]. According to the World Health Organization (WHO), CAD will be one of the four leading causes of death in the world in 2030. Global cardiovascular deaths will increase from 17.1 million in 2004 to 23.4 million in 2030 [2]. CAD mainly results from coronary atherosclerosis. Atherosclerosis is a condition whereby the arteries become narrowed and hardened due to an excessive build-up of plaque around the artery wall. Removal of the atherosclerotic plaque is currently performed by invasive techniques, such as percutaneous transluminal coronary angioplasty (PTCA), atherectomy, and stenting. However, all of these techniques can trigger a process known as 
restenosis whereby the vessel closes upon itself again via a different mechanism than the original injury. Systemic therapy, using antiproliferative and anti-thrombotic drugs, has proven ineffective for this condition $[3,4]$. Systemic therapy may be unable to deliver sufficiently high drug concentrations at the injury site without causing serious side-effects in non-target tissues [5]. To overcome this problem, the insertion of a bare-metal stent (BMS) at the time of the intervention has been undertaken to prevent elastic recoil and reduce the incidence of restenosis [6]. However, several limitations and side-effects have been associated with coronary stenting. First, stents cause permanent physical irritation with the risk of long-term endothelial dysfunction or inflammation [7]. Second, stents are highly thrombogenic [8]. Third, stents prevent the vessel from remodeling and functioning in a normal physiological manner [9]. Finally, stents create difficulties for future bypass surgery and noninvasive imaging. Thus, efforts have been directed toward achieving local drug delivery to the injured blood vessel at the time of intervention using drug-eluting stents (DESs) in which a drug is released from a polymer coating or loaded directly onto the stent [10]. Drug release at the site of vascular injury achieves an effective local concentration of the drug for a certain period of time while simultaneously avoiding systemic toxicity. Although the first-generation DESs have been demonstrated to be more effective than BMSs in reducing vascular restenosis by suppressing smooth muscle cell (SMC) proliferation, their safety has been limited by suboptimal polymer biocompatibility, delayed stent endothelialization leading to late and very late thrombosis, and local drug toxicity. These findings may be partly explained by the nonselective inhibition of both endothelial cell (EC) and SMC proliferation by the antiproliferative drugs eluted from DES. Therefore, there is an urgent need to develop novel and efficacious methods of circumventing the problems seen with BMSs and DESs, and nanoparticle drug- and gene-eluting stents hold much promise [11]. This article reviews the molecular mechanism of coronary restenosis, the use of DESs, and advances in nanoparticle drug- or gene-eluting stents for the prevention and treatment of coronary restenosis.

\section{Coronary stenosis and restenosis}

\section{Coronary stenosis}

Coronary stenosis (Figure 1) is a condition in which a coronary artery becomes tapered and backed up with materials such as fat or cholesterol, typically due to coronary atherosclerosis. Atherosclerosis is a systemic disease characterized by calcification and the build-up of fatty deposits, cellular debris and cholesterol in arteries, resulting in stenosis (narrowing) of the vessels [12]. If this process occurs in coronary arteries, the insufficient delivery of oxygenated blood to the heart manifests as cardiac ischemia (angina pectoris). Unstable lesions can rupture and trigger thrombosis, which may result in myocardial infarction (a heart attack) [13].

\section{Coronary restenosis}

Coronary restenosis (Figure 2) represents the reoccurrence of stenosis, or a narrowing of a coronary artery, leading to restricted blood flow. Restenosis is considered a local vascular manifestation of the general biological response to injury [14]. PTCA-induced restenosis is thought to involve primarily negative remodeling and, in part, neointimal hyperplasia [15]. Vascular remodeling occurs naturally in the process of atherosclerosis. Human coronary arteries often enlarge in response to plaque formation as a compensatory response that limits narrowing of the vessel lumen (positive remodeling) [16]. Positive remodeling can occur after PTCA, but negative remodeling (i.e., lumen loss due to vessel constriction rather than to neointimal thickening) can also ensue, contributing to restenosis [17]. The pathogenesis of restenosis can be divided into four phases, which can take place from hours to weeks and months after PTCA: 1 ) early elastic recoil; 2) mural thrombus formation; 3) neointimal proliferation with extracellular matrix formation; and 4) chronic geometric arterial changes (months) [18].
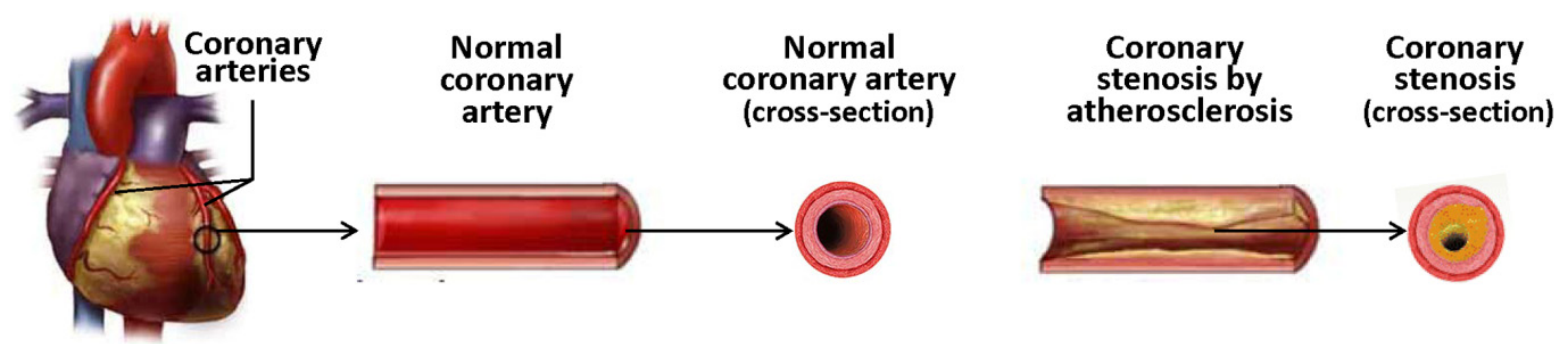

Figure I. Coronary atherosclerosis and coronary stenosis. 


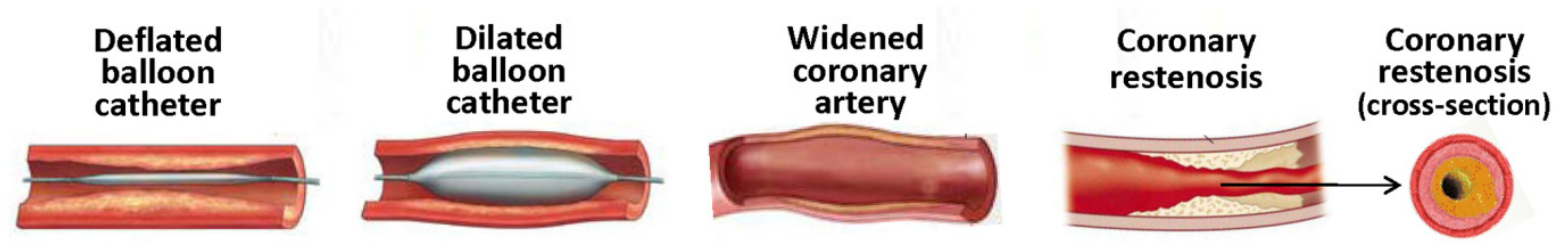

Figure 2. Percutaneous transluminal coronary angioplasty and coronary restenosis.
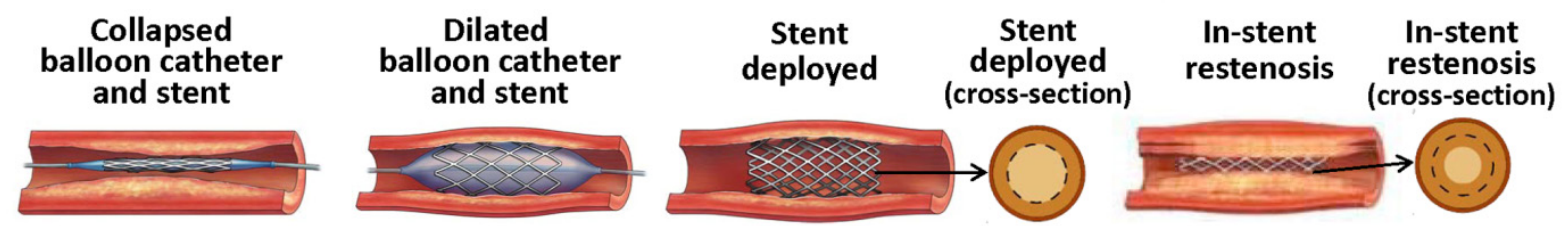

Figure 3. Stenting and coronary in-stent restenosis.

\section{In-stent restenosis}

In-stent restenosis (ISR, Figure 3), the narrowing of a previously stented coronary artery lumen, is one of the most concerning issues complicating coronary stent implantation. ISR can be defined clinically or angiographically. Clinically it is defined as the presentation of recurrent angina or objective evidence of myocardial ischemia, whereas angiographic ISR is the presence of $>50 \%$ diameter stenosis in the stented segment at angiography follow-up [19]. Traditionally, ISR has been classified on the basis of length of restenosis in relation to the stented length. Four types of ISR have been defined: I) focal ( $\leq 10 \mathrm{~mm}$ length); II) diffuse (ISR $>10 \mathrm{~mm}$ within the stent); III) proliferative (ISR > $10 \mathrm{~mm}$ extending outside the stent); and IV) occlusive ISR. Type I has been further subdivided into types IA to ID based on the site of focal ISR in relation to the stent [20]. An additional type of ISR has been proposed, that of "aggressive ISR," defined as ISR that is longer and/or more severe than the original lesion. This type is noteworthy in that the clinical course is not benign, with these patients more likely to develop more severe symptoms and higher rates of myocardial infarction [21]. Restenotic lesions caused by stents and angioplasty are very different at the molecular level, although clinically the pathological outcome is the same [22]. Restenosis caused by balloon angioplasty is attributed to three different factors: the elastic response that occurs after the overstretching of the vessel, neointimal hyperplasia, and negative remodeling [22]. Neointimal formation associated with balloon angioplasty is primarily formed by the adventitia, with some proliferation of the media layer. Stent-induced restenosis is primarily caused by SMC proliferation and accumulation in the intimal layer, leading to neointimal growth [23]. Vascular remodeling in this case is not as defined as in balloon-induced injury [24]. Compared to restenosis after balloon angioplasty, the pathophysiology of ISR is also different, with a more profound cellular and proliferative response and less thrombogenic potential.

\section{Molecular mechanism of restenosis}

The cell types involved in the restenotic process are well documented. There are three primary layers in a healthy blood vessel. The tunica intima or intimal layer is the innermost layer and is in contact with the blood flowing through the artery. This layer consists primarily of ECs. Adjacent to the intimal layer is the tunica media or medial layer, consisting of primarily SMCs. This layer is responsible for the vascular tone. The outermost layer is the tunica adventitia or adventitial layer, consisting of primarily collagen, to provide structure and elasticity. Balloon inflation fractures the atherosclerotic plaque, invoking platelet adhesion, aggregation and activation. Activated platelets release various cytokines, chemokines and growth factors, which initiate SMC proliferation, leukocyte recruitment and activation of the coagulation cascade (Figure 4). SMCs undergo a phenotypic modulation from a contractile to a synthetic phenotype (dedifferentiation), proliferate into the media, migrate from the media into the intima, and subsequently form the neointima. Various inflammatory cells such as monocytes, T-cells and a small number of B-cells are also recruited [25]. There is a degree of similarity between restenosis and wound healing. Analysis of the extracellular matrix of a restenotic lesion reveals hyaluronan and collagen, which are also both involved in the wound healing process [26]. 


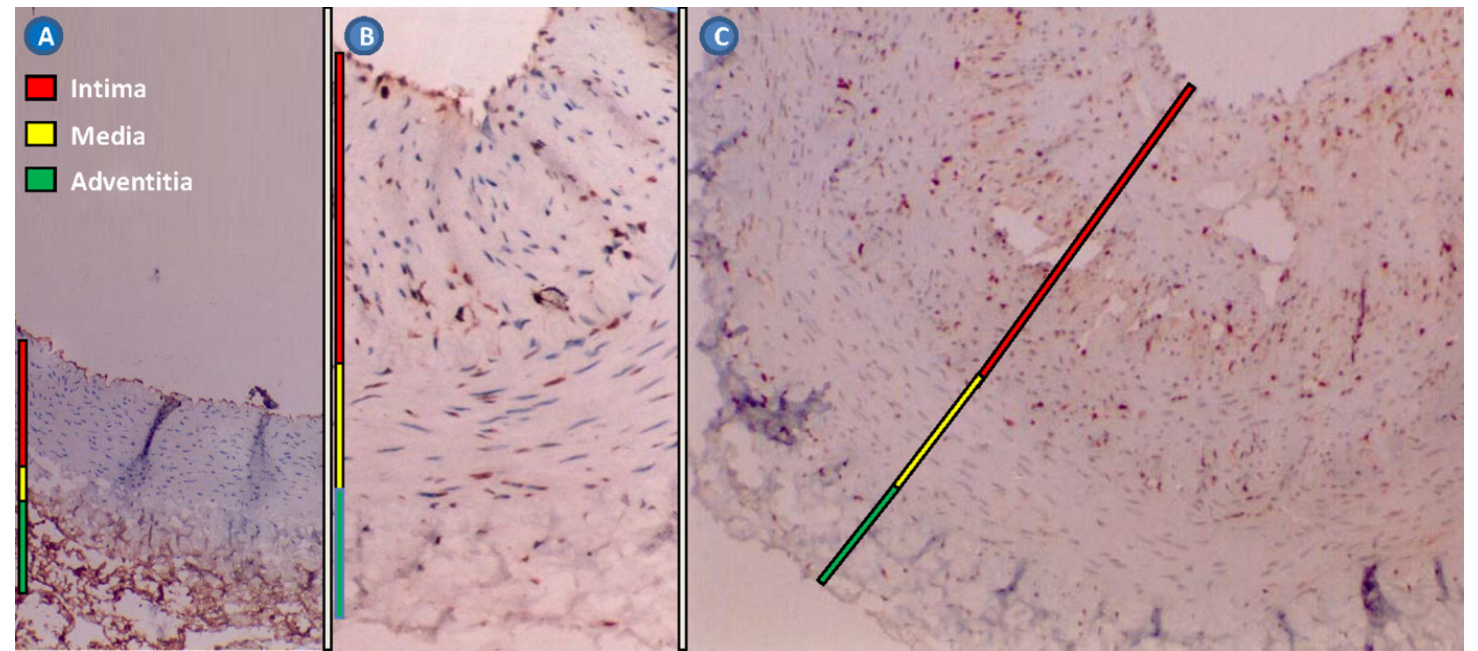

Figure 4. Rabbit restenotic model developed by balloon-injured abdominal aorta and high cholesterol diet. (A), normal abdominal aorta (Hematoxylin staining $\times$ 100); (B), restenotic abdominal aorta. The intima and media were significantly thickened (Immunohistochemical staining for proliferating cell nuclear antigen $\times 100$ ); and $(C)$, restenotic abdominal aorta. Proliferating cell nuclear antigen-positive cells and various inflammatory cells were found in the thickened intima (Immunohistochemical staining for proliferating cell nuclear antigen $\times 100$ ).

There are a number of growth factors and cytokines that play a role in restenosis. Fibroblast growth factor (FGF)-2, platelet-derived growth factor (PDGF) $A$ and $B$, insulin like growth factors (IGF)-1, and transforming growth factor $\beta$ (TGF- $\beta$ ) are produced by SMCs and are responsible for the SMC proliferation [27]. Additionally, PDGF A and B, released from SMCs, platelets, and ECs, are responsible for SMC migration. Vascular endothelial growth factor (VEGF) is responsible for endothelialization and angiogenesis. The cytokines involved in restenosis are monocyte chemoattractant protein-1 (MCP-1), interleukin (IL)-1, IL-6, IL-8, thrombin, adenosine diphosphate, serotonin, and thromboxane A2 [27]. These cytokines, which are present early in the process, are responsible for monocyte and neutrophil recruitment and are derived from a number of cells such as macrophages, SMCs, ECs, fibroblasts, T-cells and polymorphonuclear leukocytes. The cytokine signals are key indicators of an inflammatory response at the site of damage. Another molecular signal associated with inflammation and restenosis is the $\beta_{2}$-integrin molecule Mac- 1 (CD11b/CD18), which is responsible for monocyte recruitment [21]. At the same time, the expression of mitogenic proto-oncogenes such as c-fos, c-jun, fosB, junB, and junD in the SMCs is increased [28]. In addition to the inflammatory factors mentioned, other proteins or enzymes are effected by restenosis, including p27, p70, p16, and collagen [29].

\section{Traditional and nanoparticle drug-eluting stents}

\section{Therapeutic drugs}

There are many ways to treat coronary stenosis and restenosis. Drugs with anti-inflammatory, anti-thrombogenic, antiproliferative and immunosuppressive characteristics are all candidates for use in DES, which aim to prevent stent restenosis. Drugs with the above-mentioned characteristics may inhibit one or more pathways associated with restenosis [30]. A variety of different drug classes have been employed for the prevention of SMC growth and proliferation. These drugs include SMC growth inhibition agents: cytarabine, doxorubicin, vincristine [31], dalteparin sodium, cyclosporine A, colchicines, etoposide [32], sirolimus (rapamycin) [33], paclitaxel [34], and ceramide [35]; antiplatelet drugs: cilostazol, eptifibatide and tirofiba [36,37]; potential anti-inflammatory agents: clodronate, pamidronate, alendronate, and ISA-13-1 [38,39]; PDGF receptor specific drugs: tyrphostin (AG-1295 and AGL-2043) [40,41]; and others: estrogen [42], troglitazone [43], tranilast [44], valsar$\tan$ [45], statins [46], heparin, hirudin [47]; and the Fab fragment inhibitor abciximab [37]. Six Limus family-related drugs are currently being studied in DESs, namely sirolimus, everolimus, biolimus A9, zotarolimus, tacrolimus, and pimecrolimus. Sirolimus, everolimus, biolimus A9, and zotarolimus all bind to the FK binding protein 12 (FKBP12), which subsequently binds to the mammalian target of rapamycin (mTOR) and thereby blocks the cell cycle of SMCs, mainly at the transition from the G1 to the $S$ phase. The mechanisms of action of tacrolimus and pimecrolimus differ. Both drugs bind to FKBP506. The tacrolimus/pimecrolimus FKBP506 complex subsequently inhibits the calcineurin receptor, which leads to decreased cytokine expression on the cell surface membrane and results in an inhibition of T-cell activation and lower SMC selectivity (Figure 5). 


\section{Sirolimus (rapamycin)}

The first of the Limus family drugs used on endovascular prosthesis was sirolimus, a natural macrocyclic lactone that binds to specific cytosolic proteins called FKBP12 that block G1 to $S$ cell cycle progression by inhibiting the activation of a protein known as mTOR $[48,49]$. This step also suppresses cytokine-driven T-cell proliferation (Figure 5A). Sirolimus is an immunosuppressive and antiproliferative drug that is traditionally used to prevent organ transplant rejection. Several successive studies confirmed the efficacy of sirolimus-eluting stents [50,51]. Novolimus is a metabolite of sirolimus and represents another new antiproliferative mTOR inhibitor specifically developed for the stents. The newly developed novolimus-eluting stents have been tested in a clinical study, demonstrating superiority over zotarolimus-eluting stents with regard to angiographic in-stent late loss [52].

\section{Everolimus}

A second derivative of the Limus family is everolimus, a sirolimus analog with a single minimal alteration in its molecular structure (position 40) without a chemical modification of the mTOR binding domain. Everolimus, like rapamycin, blocks growth factor derived cell proliferation, arresting the cell cycle at the G1 to S phase (Figure 5A). More specifically, at the cellular level, everolimus forms a complex with the cytoplasmic protein FKBP12. The complex inhibits the growth factor-stimulated phosphorylation of two proteins involved in the initiation of protein synthesis, the p70 s6 kinase and 4E-BP1. The phosphorylation of these two proteins is controlled by mTOR. This detail indicates that everolimus interferes with the same pathway as does sirolimus. However, the everolimus effect is not restricted to T-lymphocytes, but potentially affects other cells, such as SMCs $[53,54]$. Of note, when implanted in rabbit iliac arteries, everolimus-eluting stents demonstrate more rapid endothelialization than do sirolimus-, zotarolimus-, or paclitaxel-eluting stents, as shown by the complete endothelialization of the struts with cd31 exhibition (antigen surface marker of good endothelial functionality) in the cells at 14 days [55].

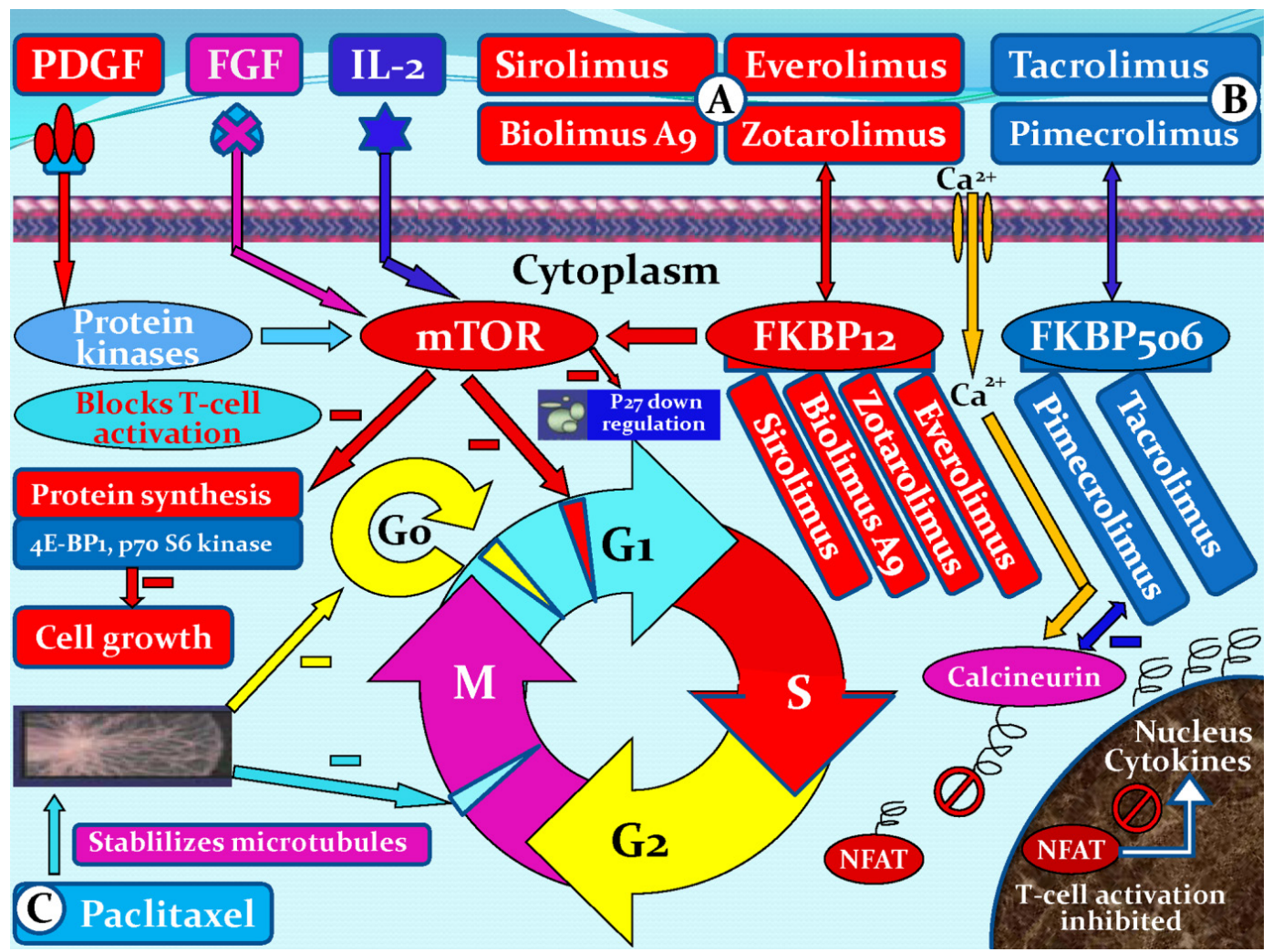

Figure 5. Mechanisms of action of six Limus family-related drugs (sirolimus, everolimus, biolimus A9, zotarolimus, tacrolimus, and pimecrolimus) and paclitaxel. (A), sirolimus, everolimus, biolimus A9, or zotarolimus forms a complex with the cytoplasmic protein FKBPI2. The complex inhibits the growth factor-stimulated phosphorylation of two proteins, the p70 s6 kinase and 4E-BPI. The phosphorylation of those two proteins is controlled by the mammalian target of rapamycin (mTOR). (B), tacrolimus or pimecrolimus binds to FKBP506, forming a complex, which binds to and blocks calcineurin. The complex inhibits the activation of nuclear factor of activated T cells (NFAT), thus preventing its entrance into the nucleus and inhibiting T-cell activation. (C), paclitaxel is a microtubule inhibitor. It binds to $\beta$-tubulin proteins in the mitotic spindle, rendering them non-functional and thereby inhibits cell division in the G0/GI and G2/M phases. PDGF, platelet-derived growth factor; FGF, fibroblast growth factor; FKBP, FK binding protein; G0, G0 phase (resting phase); GI, GI phase (cell enlarges and makes new protein); G2, G2 phase (preparation for division); M, M phase (cell division or mitosis); S, S phase (DNA replication). 


\section{Zotarolimus}

A third descendant of the Limus family used on coronary stents, also with a change on position 40 , is zotarolimus (ABT-578). Zotarolimus is a tetrazole-containing macrocyclic immunosuppressant and potent antiproliferative agent. It inhibits the protein phosphorylation events associated with mRNA translation and cell cycle control (Figure 5A). However, zotarolimus is suggested to have higher tissue retention compared with the sirolimus-eluting stent. Of note, recent data on endothelial function after stent placement in porcine coronaries showed normally functioning endothelium at 1 and 3 months after zotarolimus-eluting stent implantation [56].

\section{Biolimus A9}

Biolimus A9 is also a sirolimus derivative that inhibits growth factor-driven cell proliferation, such as T-cells and vascular SMCs (Figure 5A). In addition to its anti-inflammatory and antiproliferative potential and improved pharmacokinetic profile, the increased lipophilicity of biolimus A9 improves uptake by the coronary vessel wall, resulting in a more localized effect and lower systemic drug exposure [57] than sirolimus eluted from the Cypher ${ }^{\circledR}$ stent $[58,59]$. Compared with first-generation DESs, biolimus A9-eluting stents have been shown to be associated with better recovery of endothelial function in coronary arteries, a finding that could be partly explained by the better drug release kinetics [60].

\section{Tacrolimus}

Tacrolimus (FK506, Prograf) is a water-insoluble macrolide immunosuppressant produced by Streptomyces tsukubaensis. It has been widely used to reduce the incidence and severity of allograft rejection after organ transplantation and to treat other inflammatory conditions such as atopic dermatitis. Tacrolimus is a noncytotoxic $\mathrm{T}$ cell inhibitor that maintains cells in the G0 or resting phase. In this situation, cells are able to function but unable to replicate. The end result of tacrolimus is a reduction in the activation of cytokine genes (Figure 5B). In contrast to sirolimus, tacrolimus demonstrates far more potent inhibition of SMCs than of ECs $[9,61]$. The JUPITER II trial investigated the safety and efficacy of the Janus ${ }^{\mathrm{TM}}$ tacrolimus-eluting carbostent compared to the bare metal Tecnic $^{\mathrm{TM}}$ carbostent. A total of 332 patients were enrolled in 17 European centers and randomized to either the Janus ${ }^{\mathrm{TM}}$ tacrolimus-eluting carbostent (166 patients) or the bare metal Tecnic ${ }^{\mathrm{TM}}$ carbostent (166 patients). Early clinical outcomes demonstrated low major adverse cardiac events (MACE) rates in both groups. These results were sustained up to 6 months in follow-up [62].

\section{Pimecrolimus}

Although a part of the Limus family, pimecrolimus does not block mTOR and inhibits EC proliferation to a much lesser degree (Figure 5B) [63]. The safety and efficacy of a pimecrolimus-eluting stent have been evaluated in a porcine coronary model and in a phase I clinical trial. At 28 days and 3 months in the porcine model, histopathologic indicators predicted safety and biocompatibility when stents coated with polymer only, drug only, and 2 drug-polymer formulations were compared with BMS. In the phase I clinical trial, 15 patients had successful implantation of pimecrolimus-eluting stents. By 6 months, no patient had suffered death, myocardial infarction, or stent thrombosis. However, the angiographic restenosis prevalence $(61 \%)$, mean late loss $(1.44 \mathrm{~mm})$, and repeat target lesion revascularization prevalence (53\%) were significantly higher than those of historical BMS controls. Whereas the primary end point was percent volume obstruction, restenosis was so severe that the operators performed intravascular ultrasound examination in only 6 patients [64]. These results suggest that pimecrolimus-eluting stents induced an exaggerated neointimal hyperplasia at 6 months in comparison with historical controls.

\section{Paclitaxel}

A non-Limus family-related drug widely studied for its efficacy in coronary stents is paclitaxel. Its effect has been mainly explained by its ability to stabilize microtubules and thereby inhibit cell division in the G0/G1 and G2/M phases [65]. Additionally, paclitaxel affects cell motility, shape, and transport between organelles (Figure 5C). Two delivery methods have been used in clinical trials, either with or without a polymer carrier. In the pivotal US trial DELIVER 1, paclitaxel was loaded without a polymer. No significant benefit was observed in the treated group, and the stent was not commercialized [66]. Boston Scientific Corporation pursued the development of paclitaxel stents eluted from a polymeric carrier. The randomized TAXUS I trial evaluated the safety of the TAXUSTM-NIRx ${ }^{\mathrm{TM}}$ stent system [67] and was followed by TAXUS II [68], TAXUS IV [69,70], TAXUS V, and TAXUS VI [71]. An integrated analysis of the TAXUS trials shows that the paclitaxel-eluting TAXUS Express stent effectively inhibits in-stent neointimal proliferation, even in high-risk and overlapping stent patients [71].

\section{Actinomycin D}

Actinomycin D is an antibiotic used in malignant neoplasms due to its antiproliferative character. It affects the $S$ phase of the cell cycle and is a potent inhibitor of cell proliferation. The efficacy of actinomy- 
cin-eluting stents was investigated in the ACTION study; however, the study was terminated prematurely due to the increased rate of stent restenosis [72]. This increase was attributed to local drug toxicity.

\section{Dexamethasone}

Dexamethasone is a potent anti-inflammatory agent that is used for a variety of inflammatory and immune diseases. It can inhibit the proliferation of fibroblasts, SMCs and macrophages [73]. The activated receptor-dexamethasone complex then migrates to the nucleolus, where it binds to glucocorticoid response elements in the DNA. Glucocorticoids also exert an effect on the prostaglandin synthesis pathway, which is responsible for the production of the lipid-inflammatory mediators. Preclinical studies have found dexamethasone-eluting stents to be safe and beneficial in terms of stent-induced inflammation. In the clinical setting, the STRIDE (STudy of anti-Restenosis with the BIodivYsio Dexamethasone-Eluting stent) trial evaluated the safety and the efficacy of the BiodivYsio Matrix LO stent ${ }^{\mathrm{TM}}$ loaded with dexamethasone $\left(0.5 \mu \mathrm{g} / \mathrm{mm}^{2}\right.$ of stent). During the 30-day follow-up, one of the 71 patients developed a non-Q-wave myocardial infarction. At 6-month follow-up, two patients presented with recurrence of symptoms. Both showed a significant restenosis in the study stent, treated with balloon angioplasty. The six-month restenosis rate was $13.3 \%$ with a late loss of $0.45 \mathrm{~mm}$ [74].

\section{Terumo statin}

Preliminary experiments have shown that statins have a potent antiproliferative effect on SMCs [75]. Rosuvastatin can effectively inhibit in-stent neointima formation and in parallel improves endothelial dilator function, both in the presence and absence of high angiotensin II (Ang II) levels [46,76]. Currently, animal studies are exploring the utilization of the Tsumani $^{\mathrm{TM}}$ stent (Terumo Corporation, Tokyo, Japan) as the platform for local simvastatin delivery.

\section{Stent coatings}

DESs often utilize polymers as a foundation upon which to incorporate pharmacologic agents. Synthetic or biological polymers can be used as matrices for drug incorporation, but concerns have been raised regarding biocompatibility, sterility or potential induction of inflammation. Currently, alterations on stent-backbone design (biodegradable, bioabsorbable, nanoporous, etc.) are being explored. Polymers can be broadly divided into two categories: biodegradable and non-biodegradable. Non-biodegradable polymers include phosphorylcholine (PC) polymer (Endeavor ${ }^{\circledR}$ stent, Medtronic); C10, C19 and polyvinyl pyrrolidone (PVP) (BioLinx polymer system); parylene $\mathrm{C}$, polyethylene-co-vinyl acetate (PEVA), and poly n-butyl methacrylate (PBMA) (CYPHER ${ }^{\mathrm{TM}}$ stent, Cordis); poly(styrene-b-isobutylene-b-styrene) (TAXUS ${ }^{\circledR}$ stent, Boston Scientific); PBMA and polyvinylidene fluoride hexafluoropropylene (PVDF-HFP) (Xience $\mathrm{V}^{\circledR}$ stent, Abbott Vascular; PROMUSTM Element $^{\mathrm{TM}}$, Boston Scientific). Non-biodegradable polymers are currently still the preferred coating of choice for stents. This coating ensures that metal struts do not come into contact with the blood, thus minimizing restenosis. Biodegradable polymers consist of poly-L-lactide (PLA), polyvinyl pyrrolidone, poly lactide-cocaprolactone (PLC), and poly lactide-co-glycolide (PLGA) (Supralimus181 and Infinnium 181 stent, Sahajanand Medical Technologies); poly-L-lactic acid (PLLA) (Excel stent, JW Medical System). Currently, the use of biodegradable polymers is largely experimental and not approved by the FDA, and the actual benefits of having a biodegradable polymer coating over a non-biodegradable one remains to be seen [11].

Bioresorbable stents are devices designed to provide temporary architectural support for the vessel wall but are fully biodegradable. The polymers of bioabsorbable stents are often composed of polylactides such as polylactic acid or polycarbonate. They are completely metabolized in approximately 12 to 18 months. The initial polymer-based bioresorbable stents were tested in animals and produced marked inflammation resulting in enhanced intimal hyperplasia and thrombosis [77]. Lincoff et al. [78], however, demonstrated in a porcine model that stents composed of poly-L-lactide (PLLA) produced minimal inflammation and durable results. Bioresorbable alloy stents, most commonly composed of magnesium, have been used both in animals and clinically. Magnesium has been the chosen alloy because it is an essential mineral well tolerated by the body and it absorbs over four months. Metallic bioresorbable stents have specific advantages over polymer-based analogs including increased strength, more rapid degradation, and complete radioopacity; importantly, metal alloys also produce only a minimal inflammatory response. Bioresorbable Vascular Scaffold (BVS) (Abbott Vascular) is composed of poly-l-lactic acid and poly-D, L-lactide and contains everolimus. It requires more than 2 years for complete absorption. The REVA stent (REVA Medical) is composed of a bioabsorbable tyrosine polycarbonate polymer and metabolized into amino acids, ethanol and carbon dioxide in approximately 36 months.

\section{Hydroxyapatite}

In a search for more biocompatible coatings, hydroxyapatite was found to be a valuable alternative 
as a polymer surrogate. Hydroxyapatite is a well-known and excellent bioceramic that closely resembles biological apatite (bone); it is biocompatible, bioactive, and bioresorbable, and it forms the basis of a polymer that is only $200 \mathrm{~nm}$ thick [79]. Furthermore, its porous structure makes it an ideal drug carrier.

\section{Hyaluronic acid}

Hyaluronic acid (HA) is highly compatible with cells and the cellular matrix. It can be efficiently degraded using specific enzymes, such as hyaluronidase; furthermore, its degradation products can induce extracellular matrix production and the neoformation of blood capillaries [80-82]. HA enhances the proliferation and migration of ECs at a later stage, whereas Akt1 siRNA delivered from nanoparticles can knock down the initial over-growth of SMCs near the implanted stent.

\section{Poly (lactic-co-glycolic acid)}

Poly (lactic-co-glycolic acid) (PLGA) is a biodegradable polymer that has been approved by the FDA to be used in medicine and medical devices. PLGA nanoparticles (NPs) have exhibited slow releasing capability for hydrophobic drugs and have also been tested extensively for DNA delivery in gene therapy $[83,84]$. The incorporation of NPs into the polymer coating layer on DESs improved drug release profiles $[85,86]$. Previous study has shown that stents coated with NPs of DNA polyplexes were able to efficiently transfect and express the transgene in stent-contacting arterial tissue, but not in adjacent arterial segments or distal organs [87], suggesting the flexibility of DNA $\mathrm{NP}$-coated stents for localized gene delivery.

\section{Polylactic acid}

The most studied biodegradable polymers are polylactic acid and polylactic-co-glycolic acid, which degrade over time and could, therefore, eliminate the problems associated with lack of polymer biocompatibility and polymer-induced inflammation. To date, several biodegradable polymer stents eluting biolimus A9, sirolimus, or paclitaxel have been clinically evaluated, so far proving to be effective and safe in the short term ( $\leq 30$ days) and midterm $(\leq 1$ year) [88-90].

\section{Poly-I-lactic acid (PLLA)}

The Igaki-Tamai stent (Igaki Medical Planning Co, Ltd) is a coil stent made of poly-1-lactic acid (PLLA) monofilament with a zigzag helical design [91]. The stent strut thickness is $0.17 \mathrm{~mm}$. The length of the stent is $12 \mathrm{~mm}$ and, in its expanded state, the stent covers $24 \%$ of the vessel area. The stent has 2 radiopaque gold markers to facilitate the identification of both ends of the prosthesis. Deployment of the stent is currently achieved with a balloon-expandable system through an 8 French guiding catheter. Although, PLLA biodegradable stent implantation is feasible, safe, and effective in humans, long-term follow-up with more patients will be required to validate their long-term efficacy.

\section{Polyzene-F}

Polyzene-F is highly biocompatible and possesses anti-inflammatory, bacteria-resistant, and pro-healing qualities. The coating ensures that the stent has a very low surface thrombogenicity, potentially reducing the risk of stent thrombosis. Evaluation of cobalt chromium stents nanocoated with polyzene-F in an animal model yielded favorable results [92]. Preliminary studies evaluating the Catania ${ }^{\mathrm{TM}}$ (CeloNova Biosciences, Newnan, GA, USA) stent in humans demonstrated a good safety profile and high-level efficacy $[93,94]$.

\section{Stent platforms}

Stents are prepared to be flexible and easily expandable and have pores for the lateral branches. Stent design influences short- and long-term outcomes. Stainless steel was used as the stent platform in the first generation DESs (Cypher ${ }^{\circledR}$, Cypher Select ${ }^{\circledR}$; Cordis Corporation, FL, USA or Taxus ${ }^{\circledR}$ Express/LibertéTM; Boston Scientific, MA, USA), whereas cobalt chromium was used in the second generation DESs (Endeavor ${ }^{\circledR}$ Resolute; Medtronic, MN, USA; Xience ${ }^{\mathrm{TM}} \mathrm{V}$, Xience PRIMETM; Abbott Laboratories, IL, USA; and Promus ${ }^{\mathrm{TM}}$, Promus Element ${ }^{\mathrm{TM}}$, Boston Scientific). Cobalt chromium alloy strengthens the stent andallows for strut thickness while maintaining radioopacity. It has lower risk for allergy because it contains less nickel compared to stainless steel [95]. Stainless steel or nitinol was used in the third generation stents (biolimus A9) with biodegradable polymers. Two different delivery systems have been explored, with and without additional coatings. Uncoated metal stents that have a drug attached to their surface or embedded within macroscopic fenestrations or microscopic nanopores, enabling rapid drug delivery, are under investigation and are not yet commercially available. Metal stents coated with an outer layer of polymer (bioabsorbable or non-bioabsorbable) can be drug-loaded, thus providing more controlled and sustained drug delivery, which might allow for more optimal drug-tissue interactions [96].

\section{Common stent platforms}

There are many different delivery systems. The common stent platforms are as follows: 1) The Amazonia PAX (MINVASYS, Paris, France) integrates a Cobalt Chromium coronary stent, Amazonia CroCo, a 
well-tested antiproliferative agent and the polymer-free paclitaxel (PAX) technology. 2) The BioFreedom Drug-Eluting Coronary Stent Delivery System (Biosensors Inc, Newport Beach, Calif) is composed of 3 key components, including a $316 \mathrm{~L}$ stainless steel platform that has been modified with a proprietary surface treatment resulting in a selectively microstructured, abluminal surface. 3) The BioMatrix stent (Biosensors Inc, Newport Beach, Calif) is a novel DES that incorporates the S-Stent platform, a thin, stainless steel, laser-cut, tubular stent with $16.3 \%$ to $18.4 \%$ metal surface area. The antiproliferative drug is biolimus A9, a highly lipophilic, semisynthetic sirolimus analogue with an alkoxy-alkyl group replacing hydrogen at position 42-O. 4) The Sparrow Coronary Stent System (CardioMind, Inc, Sunnyvale, Calif) is a 0.014-inch guide wire-based stent delivery platform combining a limus drug in a biodegradable polymer matrix on the CardioMind nitinol stent platform with a novel release mechanism that uses a principle of electrochemical dissolution for stent release. 5) The Elixir Medical Drug-Eluting Coronary Stent Systems (Elixir Medical Corp, Sunnyvale, Calif) are designed to optimize safety and efficacy through the combination of a cobalt chromium stent platform, a low polymer loading with a controlled release and a low pharmacological drug dose. 6) Boston Scientific has recently developed the JACTAX DES system (Boston Scientific Corp, Natick, Mass) comprising the market-approved stainless steel (316 L) Liberte' premounted stent (Boston Scientific) and the antiproliferative agent paclitaxel in a reduced dose coupled with the ultrathin polymer delivery system. 7) Nevo (Cordis Corporation, Johnson \& Johnson, Warren, NJ) is a cobalt-chromium stent dotted with "reservoirs" that can be loaded with 1 or more drugs and polymers to release drug more specifically, potentially in various doses or formulations. In the case of the Nevo, the reservoirs are filled with a biodegradable polymer impregnated with sirolimus. 8) The CID OPTIMA new-generation DES system offers the combination of a patented polymer-free drug reservoir and the proven antithrombotic and potentially pro-healing integral Carbofilm coating. The key feature of the OPTIMA (CID S.r.l., Saluggia, Italy) are the absence of any polymer to carry the drug (tacrolimus), the proprietary drug-release system with reservoirs on the stent outer surface, ensuring targeted release only towards the vessel wall, and the integral Carbofilm coating that favors early endothelialization of the deployed stent and minimizes the risk of stent thrombosis. 9) Polymer-Free DES systems are intended not only to carry antiproliferative drugs but also to control their release. 10) The Genous ${ }^{\mathrm{TM}}$ Bio-engineered $\mathrm{R}$ stent $^{\mathrm{TM}}$ (Orbus-Neich Medical, Inc, Fort Lauderdale, Florida) is developed to enhance the accumulation of endothelial progenitor cells at the site of arterial injury after stent implantation to rapidly create a functional endothelial layer and thus reduce potential thrombosis and restenosis. 11) Supralimus and Supralimus-Core sirolimus-eluting stents (Sahajanand Medical Technologies Pvt Ltd, India) are new generation DESs that combine a thin stainless-steel platform (Supralimus) or cobalt-chromium platform (Supralimus-Core), a potent immunosuppressant agent (Sirolimus), and biodegradable drug-carrier components. 12) The VestaSync Hydroxyapatite Non-Polymer-Based Sirolimus-Eluting Stent System (MIV Therapeutics, Atlanta, Ga) comprises 3 basic components: a platform, an antiproliferative agent, and a drug carrier. 13) The YUKON ChoiceDES (Translumina, German) is a stent especially designed for the nonpolymeric application of antiproliferative, anti-inflammatory, and/or antithrombotic drugs. The surface of the YUKON ChoiceDES contains micropores to enable the adsorption of different organic substances. The coating solution fills the pores completely and creates a uniform layer after the evaporation of the solvent. After the drug is fully released, the microporous PEARL surface favors endothelial cell adhesion (Figure 6) [97].

\section{New stent platforms}

There are many new stent platforms. The Element Stent Platform (Boston Scientific) is made of a platinum-chromium alloy. It is a denser alloy than cobalt-chromium or stainless steel. It has a strut thickness of $81 \mu \mathrm{m}$ and exhibits high radial durability and radiopacity. The Element Platform has been used in two stents: an everolimus-eluting stent (PROMUS Element; Boston Scientific) and a paclitaxel-eluting stent (TAXUS Element; Boston Scientific). In a randomized, multicenter PLATINUM study comprising 1,530 patients, the PROMUS Element was compared with the cobalt-chromium PROMUS everolimus-eluting stent (Boston Scientific) and no significant difference was found in terms of target vessel revascularization, stent thrombosis, and cardiac events [98]. Moreover, no significant difference was found in terms of one-year outcomes between the paclitaxel-eluting TAXUS Element and the TAXUS Express stent in the TAXUS PERSEUS Workhouse study [99]. 


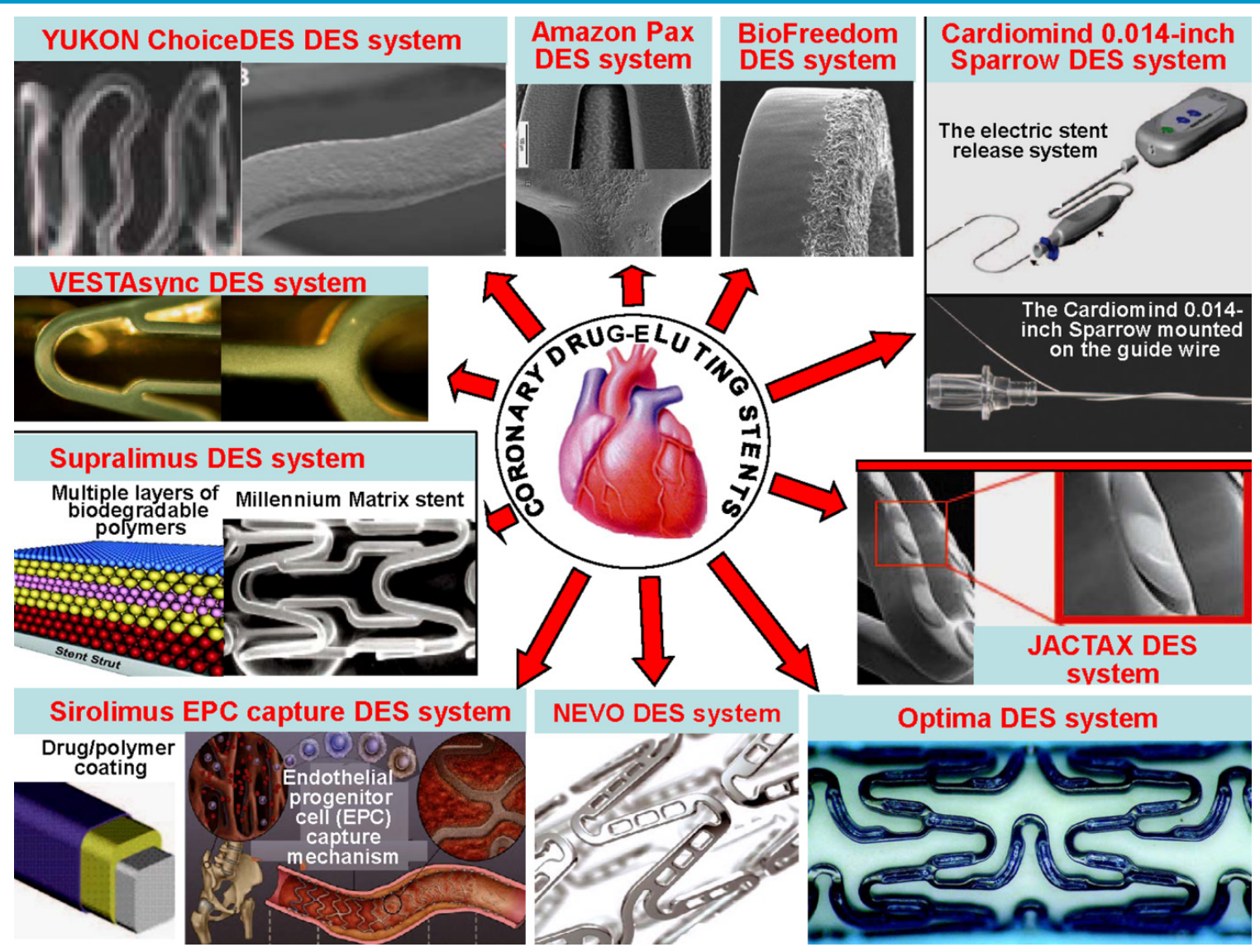

Figure 6. Several common delivery systems for the treatment of coronary restenosis

Bifurcation stents have been designed to overcome the difficulties encountered during bifurcation procedures. The rate of restenosis ranges between $28 \%$ and $54 \%$, notably because the first generation bifurcation stents (Multi-Link Frontier ${ }^{\mathrm{TM}}$, SLK-View ${ }^{\mathrm{TM}}$, Petal ${ }^{\mathrm{TM}}$, Sideguard ${ }^{\mathrm{TM}}$, Twin-Rail ${ }^{\mathrm{TM}}$, Nile Croco $^{\mathrm{TM}}$, Tryton ${ }^{\mathrm{TM}}$, and Sidekick ${ }^{\mathrm{TM}}$ ) were not drug-eluting [100]. Paclitaxel- or biolimus-eluting stents are available among the new generation bifurcation stents. 1) The TAXUS Petal (Boston Scientific) stent is more potent and more radiopaque than is stainless steel thanks to its platinum-chromium platform. It uses the same polymer as TAXUS Express. The stent has a hole for the side-branch opening. The rate of target vessel revascularization was found to be $11.7 \%$ in the first study on humans; the rotational alignment affected the success of the procedure because it had to be performed during the procedure [101]. 2) The Axxess (Devax Inc.) stent has been designed to be self-expanding with a nickel-titanium platform and a cone-shape thought suitable for bifurcation anatomy. This design facilitates access to the distal branches. The biolimus A9-eluting side branch stent has a polymer coating with a drug-eluting and biodegradable character. Nine-month outcomes of the DIVERGE study revealed alow cardiac event rate of $7.7 \%$ and a target vessel revascularization rate of $4.3 \%$
[102]. 3) Nile PaxTM (Minvasys) is a polymer free paclitaxel-eluting stent with a cobalt-chromium platform. It has been designed for bifurcation lesions with a hole in the middle. The early results of the BIPAX study revealed high success rates; however, the long-term results have not yet been published [103]. 4) STENTYS (Stensys S.A.S.) is a self-expanding stent with a nitinol platform and interconnections, which can be disconnectedby balloon angioplasty, to provide easy access to side branches. The OPEN I study reported its use with high success rates in coronary bifurcation lesions and impressively low rates of six-month cardiac events and late lumen loss [104].

\section{Nanoparticle drug-eluting stents}

DESs have proven to be effective in reducing the risk of late restenosis. To achieve a controlled and prolonged release of the antiproliferative agents, current DESs utilize various biodegradable as well as non-erodible polymeric blends to coat the stent surface and to serve as drug carriers. Nanotechnology could offer a new avenue for the improvement of current stent technology. The nanotechnology applications can be divided into two groups based on their therapeutic strategies: an anti-restenosis strategy to prevent SMC proliferation and a pro-healing strategy to restore functional endothelium. In the an- 
ti-restenosis strategy, in-stent neointima formation can be prevented by nanoparticle-assisted delivery of small molecular weight antiproliferative and anti-inflammatory therapeutic agents, or by heat-induced ablation of inflammatory cells with light-activatable nanoparticles. Decoupled from stents, nanoparticles may allow for spatiotemporal control of drug delivery to maximize antiproliferative effects while minimizing systemic toxicity. In the pro-healing strategy, re-endothelialization can be facilitated by using nanofibrous scaffolds that mimic the extracellular matrix in vessels, or by using magnetic nanoparticles for the enhanced delivery of cells to stent struts under magnetic fields.

A liposomal nanoparticle loaded with bisphophonate is a potent inhibitor of monocytes and macrophages. Danenberg et al. [105] reported that treatment with liposomal alendronate, a potent bisphophonate, at the time of stent implantation in a lipid-fed rabbit model resulted in significant reductions in neointimal formation and arterial stenosis. Liposomal alendronate formulations are currently being tested in a phase II, dose-finding, randomized, multi-center, prospective, and double blinded study. Kolodgie et al. [106] demonstrated a dose-dependent reduction in stent restenosis after infusion of albumin-based, paclitaxel-loaded nanoparticles (Nab-Paclitaxel). Subsequently, the systemic delivery of Nab-Paclitaxel was tested in patients undergoing BMS placement for safety and optimal dosing and was found to be well tolerated without significant toxicity [107]. Joner et al. [108] developed a novel prednisolone-encapsulated liposomal formulation targeted to chondroitin sulfate proteoglycans (CSPGs) and demonstrated preferential localization of drugs to the sites of stent-induced injury and subsequent reduction in restenosis in atherosclerotic rabbits. Likewise, Chan et al. [109] developed a collagen-IV-targeting, paclitaxel-encapsulated polymeric nanoparticles called nanoburrs and reported significant improvements in arterial stenosis after targeted nanoparticle treatment in a rat carotid injury model. In another study, Lanza et al. [110] reported similar anti-restenotic effects with paclitaxel-loaded nanoparticles targeted to tissue factor, a transmembrane glycoprotein that is over-expressed after vascular injury. Alternatively, "stents" themselves instead of injured vessels can serve as a target for nanoparticle-assisted drug delivery. Chorny et al. [85] developed a biocompatible, paclitaxel-loaded magnetic nanoparticle that is attracted to the stent struts and adjacent arterial tissues in the presence of a magnetic field, facilitating the localization of nanoparticles and effective inhibition of ISR.

Ceylan et al. [111] developed a bioactive stent coating by conjugating peptide amphiphile nanofibers with 1) an REDV epitope that selectively promotes EC adhesion and spreading over SMCs and platelets and 2) a Dopa molecule that forms a strong hydrogen bond with hydrophilic surfaces of stainless steel, thereby securely immobilizing the nanofiber on the stent surface. They reported improved EC adhesion, spreading, and proliferation on a nanofiber-coated stent compared to a BMS. Polyak et al. [112] used an alternative strategy to improve endothelial healing using magnetically responsive cell therapy. First, ECs were loaded with magnetic nanoparticles (MNP) and then injected into rats with stainless steel stents placed in their carotid arteries. When a magnetic field was applied, these MNP-loaded cells were preferentially driven to the stented area and remained attached. Although this use of magnetically responsive cells to facilitate stent re-endothelialization may provide a useful alternative for vascular healing after stent placement, further studies are warranted to assess the long-term viability and functionality of the ECs after delivery to the stent surface.

\section{AG 1295}

The tyrphostin AG1295, a selective blocker of PDGF-receptorkinase, exerts a marked inhibitory effect on the activation, migration, and proliferation of porcine and human SMCs in vitro. Local intravascular delivery of AG1295-impregnated polylactic acid-based nanoparticles $(130 \pm 25 \mathrm{~nm})$ to the site of balloon injury to porcine femoral arteries resulted in an approximately $50 \%$ inhibitory effect on neointimal formation [40].

\section{Imatinib mesylate}

PDGF plays a central role in the pathogenesis of restenosis; therefore, it was hypothesized that imatinib mesylate (PDGF receptor tyrosine kinase inhibitor) encapsulated bioabsorbable polymeric nanoparticle-eluting stents would attenuate in-stent neointima formation. The effects of imatinib-incorporated nanoparticle-eluting stents on neointima formation and endothelial healing were examined in a pig coronary artery stent model. The effects of the imatinib-nanoparticle were also examined in cultured cells. In a cultured cell study, imatinib-nanoparticles attenuated the proliferation of vascular SMCs associated with inhibition of the target molecule (phosphorylation of PDGF receptor- $\beta$ ), but showed no effect on endothelial proliferation. In a pig coronary artery stent model, imatinib-nanoparticleeluting stents markedly attenuated in-stent neointima formation and stenosis by approximately $50 \%$ as assessed by angiographic, histopathological, and intravascular ultrasound imaging analyses. Imatinib-nanoparticle-eluting stents also attenuated 
mitogen-activated protein kinase activity, but did not affect inflammation and re-endothelialization [113]. These data suggest that suppression of neointima formation by an imatinib-nanoparticleeluting stent holds promise as a molecular-targeting nanoparticle delivery system for preventing ISR.

\section{Paclitaxel}

Of the drugs investigated for restenosis prevention and treatment, only paclitaxel and sirolimus have been successfully administered through nanoparticle-based delivery systems and only in preclinical studies. Bhargava et al. [114] have evaluated the response of porcine coronary arteries to a novel paclitaxel-eluting porous carbon-carbon nanoparticle-coated, nonpolymeric cobalt chromium stent. Sixteen carbon-carbon-coated, nonpolymeric cobalt chromium stents with two different doses of paclitaxel (eight of each) were implanted in porcine coronary arteries. In addition, eight cobalt chromium stents coated with a biodegradable polymer were also studied. Animals were sacrificed 6 weeks after stent implantation and histomorphometric analysis was performed. The results were compared among the three groups of stents. The cobalt-chromium stents coated with carbon-carbon with low and medium doses of paclitaxel both demonstrated acceptable performance characteristics with respect to endothelialization, neointimal hyperplasia, percentage diameter stenosis, inflammatory response, and tendency to fibrin deposition when compared to historical data with the Cypher stent. However, the stents coated with poly (lactide) and poly (lactide-co-glycolide) biodegradable polymers and $0.7 \mu \mathrm{g} / \mathrm{mm}^{2}$ paclitaxel demonstrated poor performance. There was a significant tendency towards poor endothelialization, greater neointimal hyperplasia, percentage diameter stenosis, greater inflammatory response, and tendency to fibrin deposition $(P<0.01$ for all parameters). This preclinical evaluation demonstrates the safety and efficacy of a novel cobalt-chromium stent with a carbon-carbon coating and low and medium doses of paclitaxel.

Chorny et al. [85] demonstrated that magnetic treatment of cultured arterial SMCs with paclitaxel-loaded magnetic nanoparticles caused significant cell growth inhibition, which was not observed under nonmagnetic conditions. In agreement with the results of mathematical modeling, significantly higher localization rates of locally delivered magnetic nanoparticles to stented arteries were achieved with uniform-field-controlled targeting compared to nonmagnetic controls in the rat carotid stenting model. The arterial tissue levels of stent-targeted magnetic nanoparticles remained 4- to 10-fold higher in magnetically treated animals $v$ s. control over 5 days post-delivery. The enhanced retention of magnetic nanoparticles at target sites due to the uniform field-induced magnetization effect resulted in a significant inhibition of ISR with a relatively low dose of magnetic nanoparticle-encapsulated paclitaxel $(7.5 \mu \mathrm{g}$ paclitaxel/stent). Thus, the study demonstrates the feasibility of site-specific drug delivery to implanted magnetizable stents by uniform field-controlled targeting of magnetic nanoparticles with efficacy for ISR.

\section{Pitavastatin (Pitava)}

Statins are known to inhibit the proliferation of vascular SMCs and to promote vascular healing. Among six marketed statins, pitavastatin (Pitava) was found to have the most potent effects on vascular SMCs proliferation and endothelial regeneration in vitro. Tsukie et al. [115] formulated a Pitava-nanoparticle-eluting stent (20 $\mu$ g Pitava per stent). In a pig coronary artery model, Pitava-nanoparticle-eluting stents attenuated ISR as effectively as did polymer-coated sirolimus-eluting stents (SES). At SES sites, delayed endothelial healing effects were noted, whereas no such effects were observed in Pitava-nanoparticle-eluting stent sites. Pitava-nanoparticle-eluting stents attenuated ISR as effectively as did SES without the delayed endothelial healing effects of SES in a porcine coronary artery model. These results suggest that this nanotechnology platform could be developed into a safer and more effective device in the future.

\section{Sirolimus (rapamycin)}

The administration of drugs using biodegradable polymer nanoparticles as carriers has generated immense interest due to their excellent biocompatibility and prolonged drug release. Luderer et al. [116] determined the applicability of sirolimus-loaded biodegradable poly(D,L-lactide) (PDLLA) nanoparticles as drug carriers to prevent restenotic processes after stent implantation. The average 250-nm-sized $20 \%$ $(\mathrm{w} / \mathrm{w})$ sirolimus-loaded nanoparticles were extensively characterized with regard to in vitro degradation, biocompatibility and in vitro drug release. The particles demonstrated biphasic release kinetics consisting of a short burst release of $50 \%(\mathrm{w} / \mathrm{w})$ sirolimus payload, followed by a longer, slower release phase, which were desirable for their application as a drug delivery carrier. All presented results demonstrate the potential of sirolimus-loaded PDLLA nanoparticles as promising local and sustained drug delivery systems administered intraluminally to reduce ISR after stent implantation.

Räthel et al. [117] developed a system for post-hoc drug delivery to uncoated stents. They coupled rapamycin or a chemically similar fluorescent dye to superparamagnetic nanoparticles. The anti- 
proliferative activity of rapamycin coupled to nanoparticles was confirmed in vitro in primary porcine vascular cells. The particles were then incorporated into lipid based microbubbles. Commercially available stents were magnetized using nickel plating and were used to induce strong field gradients to capture magnetic microbubbles from flowing liquids when placed in an external magnetic field. Nanoparticle-bound rapamycin dose dependently inhibited cell proliferation in vitro. Magnetic microbubbles carrying coated nanoparticles were caught by magnets placed external to a flow-through tube. Plating commercial stents with nickel resulted in increased deposition at stent struts and allowed for widely increased distance of external magnets. The deposition depended on the circulation time and the velocity and distance of the magnets. Deposited microbubbles were destroyed by ultrasound and delivered their cargo to the targeted sites. Drugs can be incorporated into nanoparticle loaded microbubbles and thus be delivered to magnetizable stents from circulating fluids by applying external magnetic fields. This technology could allow for post-hoc drug coating of already implanted vascular stents.

\section{S-Nitrosoglutathione (GSNO)}

Acharya et al. [118] optimized the physicodynamic conditions of polymeric system as a coating substrate for DESs against restenosis. As nitric oxide (NO) has multifunctional activities, such as regulating blood flow and pressure and influencing thrombus formation, a continuous and spatiotemporal delivery of NO loaded in the polymer-based nanoparticles could be a viable option to reduce and prevent restenosis. To identify the most suitable carrier for S-Nitrosoglutathione (GSNO), a NO prodrug, stents were coated with various polymers, such as poly (lactic-co-glycolic acid) (PLGA), polyethylene glycol (PEG) and polycaprolactone (PCL), using solvent evaporation technique. Full factorial design was used to evaluate the effects of the formulation variables in polymer-based stent coatings on the GSNO release rate and weight loss rate. The least square regression model was used for data analysis in the optimization process. The polymer-coated stents were further assessed with differential scanning calorimetry (DSC), Fourier transform infrared spectroscopy analysis (FTIR), scanning electron microscopy (SEM) images and platelet adhesion studies. Stents coated with the PCL matrix displayed more sustained and controlled drug release profiles than did those coated with PLGA and PEG. Stents coated with the PCL matrix had the lowest platelet adhesion rate. Subsequently, stents coated with the PCL matrix were subjected to further optimization processes for the improvement of surface morphology and the enhancement of the drug release duration. The results of the study demonstrated that a PCL matrix containing GSNO is a promising system for stent surface coating against restenosis. The main preclinical studies of nanoparticle DESs for the prevention and treatment of coronary restenosis are summarized in Table 1.

Table I. Main preclinical studies of nanoparticle drug-eluting stents for coronary restenosis

\begin{tabular}{|c|c|c|c|}
\hline Drug & Nanocarrier system & Finding & Reference \\
\hline Imatinib mesylate & $\begin{array}{l}\text { Imatinib-nanoparticle-eluting } \\
\text { stent }\end{array}$ & $\begin{array}{l}\text { Attenuated in-stent neointima formation and } \\
\text { stenosis by approximately } 50 \% \text { in a pig coronary } \\
\text { artery stent model }\end{array}$ & $\begin{array}{l}\text { Masuda et al. } \\
{[113]}\end{array}$ \\
\hline Paclitaxel & $\begin{array}{l}\text { Carbon-carbon coated, nonpol- } \\
\text { ymeric cobalt chromium stent }\end{array}$ & $\begin{array}{l}\text { Acceptable performance characteristics, with } \\
\text { respect to endothelialization, neointimal hyper- } \\
\text { plasia, percentage diameter stenosis, inflamma- } \\
\text { tory response, and tendency to fibrin deposition } \\
\text { in porcine coronary arteries }\end{array}$ & $\begin{array}{l}\text { Bhargava et al. } \\
{[114]}\end{array}$ \\
\hline Paclitaxel & $\begin{array}{l}\text { Locally delivered magnetic na- } \\
\text { noparticles to stented arteries }\end{array}$ & $\begin{array}{l}\text { Inhibition of in-stent restenosis with a relatively } \\
\text { low dose of magnetic nanoparticle-encapsulated } \\
\text { paclitaxel ( } 7.5 \mu \mathrm{g} \text { paclitaxel/stent) in the rat } \\
\text { carotid stenting model }\end{array}$ & $\begin{array}{l}\text { Chorny et al. } \\
\text { [85] }\end{array}$ \\
\hline Pitavastatin (Pitava) & Pitava-nanoparticle-eluting stent & $\begin{array}{l}\text { Attenuated in-stent restenosis as effectively as } \\
\text { polymer-coated sirolimus-eluting stents in a pig } \\
\text { coronary artery model }\end{array}$ & $\begin{array}{l}\text { Tsukie et al. } \\
\text { [115] }\end{array}$ \\
\hline $\begin{array}{l}\text { S-Nitrosoglutathione } \\
\text { (GSNO) }\end{array}$ & $\begin{array}{l}\text { Stents were coated with various } \\
\text { polymers, such as } \\
\text { poly(D,L-lactide-co-glycolide } \\
\text { (PLGA), polyethylene glycol } \\
\text { (PEG) and polycaprolactone (PCL) }\end{array}$ & $\begin{array}{l}\text { Stents coated with PCL matrix displayed more } \\
\text { sustained and controlled drug release profiles } \\
\text { than those coated with PLGA and PEG; the } \\
\text { lowest platelet adhesion rate }\end{array}$ & $\begin{array}{l}\text { Acharya et al. } \\
\text { [118] }\end{array}$ \\
\hline
\end{tabular}




\section{Nanoparticle gene-eluting stents}

Gene-eluting stents (GESs) employ the use of stents as permanent scaffolds to achieve localized and sustained delivery of therapeutic genes to the affected vessel wall [119]. GESs have recently been proposed as a novel method of circumventing problems seen in BMSs and DESs. Utilizing nanotechnology, sustained and localized delivery of genes can mitigate problems of restenosis and late stent thrombosis by accelerating the regenerative capacity of re-endothelialization. Initial studies in the field of vascular gene therapy explored the use of catheters, such as the double balloon, single lumen porous balloon, Dispatch coil balloon, and Infiltrator nipple balloon catheters, to deliver both viral and non-viral gene vectors. Although these approaches were able to achieve localized delivery of therapeutic genes in conjunction with the balloon angioplasty procedure $[120,121]$, several major limitations (prolonged total occlusion of the target vessel; damage to the vessel wall and the induction of inflammatory responses and neointimal hyperplasia; and low levels of gene transfer efficiency) have dampened further advancement in the field. In recent years, there has been a surge of interest in and preference for balloon-expandable GESs over catheters as a platform for gene delivery. GESs represent a more appealing method for gene delivery to atherosclerotic coronary vessels for the following reasons: first, vector immobilization to stent struts allows for increased local concentration of the therapeutic drug at the targeted arterial segment without distal spread to nontarget tissue, thereby avoiding systemic toxicity and increasing the chance of effective gene transfection to adjacent cells $[120,122,123]$. Second, the therapeutic effect is targeted to the anticipated site of pathophysiological processes such as mural thrombosis and vascular SMC proliferation [123]. Third, there is already extensive clinical experience in coronary stenting procedures, making it extremely convenient to combine revascularization with gene delivery in a single procedure [124]. Fourth, stents are able to act as permanent scaffolding structures and reservoirs for prolonged vector release. Finally, stent-tethered vectors can better persist in tissues as they are physically protected from the shearing effect of blood flow [125]. Although there are several major limitations, a significant amount of work has been accomplished in the field of non-viral nanoparticle-based gene delivery. Most of the work on non-viral transfection has been performed with commercially available cationic lipid transfection reagents such as Lipofectamine ${ }^{\circledR}$ or Lipofectamine Plus ${ }^{\circledR}$. Numerous transgenes have been shown to be effective in reducing restenosis in animal models, and various modes of local gene delivery have been developed. There are four main molecular targets that researchers have focused on: reduction of neointimal hyperplasia; acceleration of re-endothelialization; inhibition of thrombosis; and reduction of inflammation. Of these targets, the inhibition of restenosis via a reduction in neointimal hyperplasia has been the most studied method.

\section{Therapeutic genes}

Gene therapy is an appealing way to prevent restenosis by delivering therapeutic genes into the vascular tissue. Many previous studies utilized either intravenous injection or balloon catheters to introduce genes and carriers to blood vessel. Unlike other gene therapies, cardiovascular gene therapy encounters the obstacle of specifically delivering therapeutic genes to the target site, not the blood circulatory system. The use of endovascular stents as scaffolds for the localized and prolonged delivery of therapeutic genes into the diseased blood vessel wall would provide a promising solution for gene therapy of ISR [126,127]. However, endovascular stent as a percutaneous gene delivery device needs to be improved upon mainly due to insufficient gene loading. Non-viral gene delivery has been considered safer than its viral counterpart. Strategies for enhancing non-viral gene delivery typically involve the complexation of plasmids with cationic polymers or lipids, which can self-assemble with DNA to form particles capable of being endocytosed by cells. Substrate-mediated delivery results in the immobilization of DNA complexed with the carrier onto the substrate. Immobilization on the target surface can enhance gene transfer by maintaining an elevated concentration of DNA within the cellular microenvironment via sustained release and by facilitating subsequent cellular internalization [128].

The modulation of genes with plasmid DNA and RNA interference has been used to modulate the local concentrations of specific signaling molecules that inhibit the growth of certain cells while promoting the growth of others. The key point for each of these therapies is to inhibit the growth of vascular SMCs while promoting re-endothelialization of the vessel, so as to reverse the injured vessel back into a healthy vessel. A variety of different gene targets have been used to treat restenosis. Restenosis gene therapies can be categorized by their method of action and their cellular target [129], e.g., antiproliferative (cytotoxic) genes: thimidine kinase, cytosine deaminase, FasL [130-135]; antiproliferative (cytostatic) genes: cdc2, cdk2, cdc2, cyclin B, p21, hRAD 50, p27, p16-p27, p53 [136-141], nonphorphorylatable $\mathrm{Rb}$, $\mathrm{Rb} / \mathrm{E} 2 \mathrm{~F}$ chimera, E2F decoy [142-145], truncated proteinkinase G (PKG) 
[146], proliferating cell nuclear antigen (PCNA) [147], early growth response factor (Egr-1), dominant-negative H-ras, Gax homeobox, GATA homeobox, interferon (INF)- $\beta$ [148-153], heme oxygenase-1 $[154,155]$, tissue inhibitor of metalloproteinases (TIMP-1), plasminogen activator inhibitor (PAI-1) [156-161]; re-endothelialization gene: vascular endothelial growth factor (VEGF) [162,163]; antithrombotic genes: hiridun [164], tissue factor pathway inhibitor (TFPI) [165-167], prostacyclin synthase (PGIS), cyclooxygenase-1 (COX-1) [168-171]; mixed mechanism genes: endothelial nitric oxide synthase (eNOS), inducible nitric oxide synthase (iNOS) [120,121,155,172-176].

\section{Delivery vectors}

Non-viral plasmid-mediated gene transfer

A large array of gene delivery vectors has been evaluated for their ability to introduce therapeutic genes into vascular tissue. Vectors for gene delivery can be broadly classified into 2 categories: viral and non-viral vectors. Non-viral vectors include naked plasmid DNA, plasmid DNA-containing cationic liposomes, and DNA-polycation complexes. Naked plasmid DNA comprises DNA encoding for the recombinant gene fused with DNA sequences permitting replication as a plasmid in bacterial hosts. 1) Naked plasmid DNA: There are many studies using naked plasmid DNA or plasmid DNA as delivery vectors [124,177-182]. Klugherz et al. [177] was the first group to report the successful use of a green fluorescent protein (GFP) plasmid DNA-coated stent to transfect rat aortic SMCs in vitro $(7.9 \%$ vs. $0.6 \%$ in controls) as well as stent-treated coronaries in a pig coronary angioplasty model in vivo. This approach was able to demonstrate successful transfection of 500 $\mu \mathrm{g}$ to $1 \mathrm{mg}$ of plasmid DNA per stent. A later study was able to demonstrate the successful delivery of a therapeutic gene, VEGF-2, also using plasmid DNA-coated stent, although at a lower DNA load per stent $(100-200 \mu \mathrm{g})$ [124]. The plasmid DNA was effectively delivered to only the stented site within 24 $\mathrm{h}$ of stent implantation, with no evidence of systemic expression. Transgene expression was detectable in the stented site up to 10 days after implantation, which was sufficient to exert a therapeutic effect. 2) Lipid nanoparticle-based gene delivery: An early study by Muhs et al. [120] examined iNOS plasmid delivery to porcine femoral and coronary stent injury models using a lipid-DNA complex (lipoplex) vector, which was produced by complexing iNOS plasmid with the cationic lipid DAC-30 [a mixture of the monocationic

lipid $3 \beta-\left(N, N^{\prime}\right.$-dimethylaminoethane)-carbamoylcholestero 1 (DAC) at $30 \% \mathrm{w} / \mathrm{w}$ and the neutral colipid dioleoyl phosphatidylethanolamine (DOPE) at $70 \%, \mathrm{w} / \mathrm{w}$ ]. Cationic lipid-mediated iNOS gene transfer combined with local delivery by an Infiltrator infusion catheter was shown to enable sufficiently high expression of iNOS protein to bring about therapeutic efficacy in diminishing neointimal formation. The group demonstrated proof of successful transfection and dose-dependent iNOS transgene expression (up to 2 $\mu \mathrm{g}$ of iNOS lipoplexes) and also confirmed correct transgene processing. Using a similar liposomal system, Brito et al. [13] examined gene delivery in a balloon-injured rabbit iliac artery restenosis model using GFP plasmid DNA-containing cationic liposomes (lipopolyplexes). GFP plasmid DNA was precondensed with poly(beta-amino ester) (PbAE) and encapsulated in cationic 1-oleoyl-2-\{6-[(7-nitro-21,3-benzoxadiazol-4-yl)-amino]hexanoyl\}-3-trimethyl ammonium propane (DOTAP) liposomes to form DOTAP-PbAE-plasmid DNA lipopolyplexes (LPP) with an approximate particle diameter of $236.2 \pm 73.5$ $\mathrm{nm}$. In a follow-up study by the same group using the same LPP vector for eNOS-encoding plasmid DNA in combination with a modified stent coating to permit sustained LPP delivery in vivo, they were able to show sufficiently high local eNOS expression (125 pg eNOS vs. $<50 \mathrm{pg}$ in controls) to bring about significant therapeutic efficacy in reducing restenosis and accelerating re-endothelialization. The results of a recent study by Sharif et al. [178] examined eNOS plasmid delivery in a balloon-injured rabbit iliac artery model using a lipid-DNA complex (lipoplex) vector similar to that used in Muhs et al. [120], which was produced by mixing lipofectin a 1:1 mixture of the cationic lipidN-[1-(2,3-dioleyloxy)propyl]-N,N,Ntrimethylammonium chloride (DOTMA) and the neutral colipid dioleoyl phosphatidylethanolamine (DOPE) $\}$ with a plasmid DNA solution. Similar to previous studies conducted by the group, expression studies demonstrated that reporter $\beta$-gal transgene expression following delivery from lipoplex-eluting stents peaked at 28 days post-stenting and was sustained until 42 days post-stenting, by which point expression had significantly decreased. In addition, viral-mimicking liposomes [such as the hemagglutinating virus of Japan (HVJ)-liposome] have also been investigated as gene vectors, and have been established to be highly reliable and superior to conventional liposomal carriers $[138,143,144,166,169$, 183,184]. 3). Polymeric nanoparticle-based gene delivery: In contrast to lipid nanoparticle-based delivery, few studies have explored polymeric nanoparticle-based vectors for intravascular gene delivery. An in vitro study by Kim et al. [122] reported greatly enhanced reporter gene transfection efficiency with the use of cationic GFP plasmid 
DNA/polyethylenimine (PEI) polyplexes adsorbed on hyaluronic acid (HA)-coated stents via strong electrostatic interactions between cationic pDNA/PEI polyplexes and anionic HA. Cationic PEI was mixed with GFP pDNA to form pDNA/PEI polyplexes with nanoparticular morphology and an average size of $282.1 \pm 89.3 \mathrm{~nm}$. Another novel polymeric nanoparticle-based gene delivery approach was described by $Z$ hu et al. [87] and involves spray-coating stents with dodecylated chitosan-plasmid DNA nanoparticles (DCDNPs). A final polymer-based gene vector that has been successfully used in intravascular gene therapy utilizes the biocompatible and biodegradable copolymer poly-DL-lactide/glycolide (PLGA), which is one of the few synthetic polymers that have been approved for use in humans [185]. PLGA nanoparticles were used as PDGF- $\beta$ receptor ODN antisense carriers in a balloon-injured rat carotid artery model. PLGA nanoparticles encapsulating ODNs have been previously shown to enhance cellular uptake via endocytosis, increase resistance to nuclease degradation, offer sustained release of ODNs, and subsequently prolong the duration of ODN antisense action. Indeed, the study by Cohen-Sacks et al. [185] was able to achieve sustained and controlled release of ODNs from the PLGA nanoparticles over a period of 1 month, which resulted in inhibition of neointimal formation over that period.

\section{Viral-mediated gene transfer}

Unlike non-viral vectors, fewer studies have investigated adenoviral vector tethering on nanoparticle surfaces [123,125,186-188]. Klugherz et al. [187] was the first group to report successful stent-based gene delivery using a replication-defective adenovirus encoding GFP. An antiadenoviral antibody tethering method was employed to bind adenoviral vectors to a collagen-coated stent to allow controlled, site-specific, localized release and improve transduction efficacy. Later studies followed suit, using a variety of methods to tether adenoviral vectors to the stent surface through highly specific affinity immobilization $[123,125,188]$. A study by Levy's group in 2008 [123] explored the possibility of using an entirely synthetic strategy to tether adenoviral vectors to BMSs, which involved the use of a bifunctional cross-linking agent (HL) to bind both the adenoviral vector and a surface-modified stent. Capsid proteins of adenovirus vectors were first covalently modified with the bifunctional HL and then tethered to the stent. Interestingly, an earlier study by the same group demonstrated that nanoparticle-adenovirus (NP-Ad) complexes formed from surface-activated polylactide
(PLA) nanoparticles covalently attached to adenovirus-binding proteins achieved significantly higher levels of gene delivery and transgene expression than that did comparable amounts of free adenoviral vectors [188]. Unfortunately, to date, there has not been a follow-up in vivo study on a local delivery strategy to deliver these nanoparticle-adenovirus complexes to the vasculature. Taken together, these studies provide strong evidence of the potential for nanotechology-based approaches to enhance existing viral and non-viral gene delivery methods.

\section{Delivery platforms}

The final element of a GES is the gene delivery platform, the purpose of which is to incorporate and elute naked plasmid DNA or DNA-containing vectors. In most studies, the gene delivery platform is a polymer stent coating, which plays a crucial role in ensuring a compatible relationship between the BMS surfaces, the vessel wall, and circulating blood $[13,119,122,124,126,177,178,181,189,190]$. Other studies, however, have explored the option of direct vector-tethering to BMS surfaces without the use of a polymer coating to prevent potential polymer-induced vascular injury and inflammatory responses $[123,125,182]$. In recent years, nanotechnology has been employed in the design of stent-based gene delivery platforms, be it in nanotextured surfaces to enhance biocompatibility and improve cell-stent interactions [191,192] or in specifically targeted, nanoscale surface topographic modifications to improve interactions with blood and enhance endothelial attachment, proliferation, and migration [158].

\section{Polymer stent coatings}

Recent in vivo studies on GESs using polymers for stent coatings have demonstrated successful gene transfer and/or substantial therapeutic effects with no evidence of significantly increased inflammation when the polymer is applied in a uniform and thin layer. Polymers investigated include both synthetic [e.g., polylactic-polyglycolic acid (PLGA)] [177] and naturally occurring [e.g., collagen, gelatin (a derivative of collagen, types A and B) and phosphorylcholine (PC)] polymers [13,119,124,127,178,181,189,190]. In most of these studies, the gene-encoding vector was attached to the stent surface by dip- or spray-coating the stent with vector-containing polymer that isa derivative of collagen. An alternative biocompatible stent coating recently investigated by Kim et al. [122] is hyaluronic acid (HA). HA, a major glycosaminoglycan component of the extracellular matrix, has been shown to reduce thrombus formation when coated onto endovascular devices. 


\section{Vector-tethering}

Despite the encouraging results obtained with the bulk immobilization of gene vectors on polymer stent coatings, several studies have opted instead for a vector-tethering strategy to exclude the need for a polymer coating [123,125,127,182]. Fishbein et al. [125] and Wang et al. [182] demonstrated effective gene delivery from BMS surfaces pretreated with polyallylamine bisphosphonate (PAA-BP) and conjugated to anti-pDNA or anti-adenoviral antibodies or recombinant D1 proteins via covalent cross-linking with $\mathrm{N}$-succinimidyl 3-(2-pyridyldithio)propionate (SPDP) [125,182]. Notably, Fishbein et al. [125] observed a nanoparticulate surface topography on PAA-BP stents with surface-tethered adenoviral vectors. This finding demonstrated that affinity-mediated vector-tethering allows for dense packing of the vector onto the stent surface.

\section{Several studies on nanoparticle GESs}

\section{Antisense oligonucleotide}

Antisense oligomers are polymers designed to interfere with the information transfer from the gene to the protein. Thus, they may target specific genetic sequences that potentially play an important role at particular stages of disease progression. AVI-4126 is a phosphorodiamidate morpholino oligomer, meaning that it is capable of binding to RNA in a sequence-specific fashion with sufficient avidity to be useful for the inhibition of the translation of the mRNA into protein in vivo, a result referred to as an 'antisense' effect. The AVI-4126 antisense oligomer blocks the expression of the c-myc protein, which is responsible for many of the pathologic processes associated with restenosis. In the experimental setting, animal studies have shown that AVI-4126 can efficiently reduce neointimal formation without inducing aneurysm formation [193]. Forty-four patients with either de novo lesions or restenosis were randomized into low dose ( $3 \mathrm{mg})$, high dose (10 $\mathrm{mg})$, and control groups. There was no in-hospital or 30-day MACE recorded in any group. Clinical follow-up was available for 25 patients. At 6 months, four patients (50\%) from the control group and $7(100 \%)$ patients from the low-dose group required target vessel revascularization (TVR). In contrast, in the high-dose group only 1 patient $(10 \%)$ required TVR. Angiographic follow-up in 25 patients showed that binary restenosis occurred in $38 \%$ of control patients, $29 \%$ of the low dose patients, and $0 \%$ of those in the high dose group [194]. These preliminary findings from this small cohort of patients require confirmation in a larger trial utilizing more sophisticated drug-eluting technologies.

\section{Akt I siRNA}

The inhibition of Akt1 has been reported to decrease the expression of caspase- 8 in ECs. The suppression of downstream Akt1 signaling proteins such as Fas ligand results in the stimulation of caspase activity and apoptosis in SMCs. The specific inhibition of Akt1 protein expression has also been demonstrated to result in the retardation of cell growth $[195,196]$. Che et al. [197] developed a new delivery technique for Akt1 siRNA nanoparticles using a hyaluronic acid (HA)-coated stent surface. For this purpose, the disulfide cross-linked low molecular polyethyleneimine (PEI) (ssPEI) was used as a gene delivery carrier because disulfide bonds are stable in an oxidative extracellular environment but degrade rapidly in reductive intracellular environments. In this study, Akt1 siRNA demonstrated efficient ionic interaction with the ssPEI carrier, which was confirmed by polyacrylamide gel electrophoresis. Akt1 siRNA/ssPEI nanoparticles (ASNs) were immobilized on the HA-coated stent surface and exhibited stable binding and localization, followed by time-dependent sustained release for intracellular uptake. Cellular viability on the nanoparticle-immobilized surface was assessed using A10 vascular SMCs, and the immobilized ASNs exhibited negligible cytotoxicity against the adhering A10 cells. Transfection efficiency was quantified using a luciferase assay; the transgene expression of Akt1 suppression through the delivered Akt1 siRNA was measured using RT-PCR and Western blot, demonstrating higher gene silencing efficiency when compared to other carriers. ASN coated on HA stents were deployed in the balloon-injured external iliac artery in rabbits in vivo. The Akt1 released from the stent were shown to suppress the growth of the smooth muscle at the peri-stent implantation area, resulting in the prevention of restenosis in the post-implantation phase.

\section{Chitosan-plasmid DNA}

The feasibility and efficiency of stents coated with dodecylated chitosan-plasmid DNA nanoparticles (DCDNPs) were evaluated as scaffolds for localized and prolonged delivery of reporter genes into the diseased blood vessel wall. Dodecylated chitosan-plasmid DNA complexes formed stable positive charged nanospheres with a mean diameter of approximately $90-180 \mathrm{~nm}$ and a zeta potential of $+28 \pm 3$ $\mathrm{mV}$. As prepared DCDNPs were spray-coated onto stents, a thin layer of dense DCDNPs was successfully distributed onto the metal struts of the endovascular stents as demonstrated by scanning electron microscopy. The DCDNP stents were characterized for the release kinetics of plasmid DNA and further evaluated for gene delivery and expression both in vitro and 
in vivo. In cell culture, DCDNP stents containing plasmid EGFP-C1 exhibited high levels of GFP expression in cells growing onto and adjacent to the stent surface. In animal studies, reporter gene activity was observed in the region of the artery in contact with the DCDNP stents, but not in adjacent arterial segments or distal organs. The DCDNP stent provides a very promising strategy for cardiovascular gene therapy [87].

\section{eNOS gene}

The gene for eNOS was transfected into a canine ex-vivo saphenous vein graft using Lipofectamine Plus ${ }^{\circledR}$ [198]. In this study, the transgene was identified with polymerase chain reaction in all eNOS-transfected grafts regardless of transfection modality. However, significant transcription of the ecNOS transgene was observed only in the group receiving $100 \mu \mathrm{g} / \mathrm{mL}$ plasmid DNA + LipofectAMINE PLUS. NOS activity increased approximately twofold in this group. Numbers of proliferating cells did not differ among ecNOS-transfected and control grafts in any transfection group. These results suggest that ecNOS transfection of veingrafts is feasible through intimal and adventitial routes with naked DNA or a liposomal vector. However, the efficient transcription of the transgene is evident at postoperative day 3 only after adventitialtransfection of $100 \mu \mathrm{g} / \mathrm{mL}$ of the gene.

\section{Prostacyclin synthase gene}

A disordered proliferative process in the vascular wall is thought to underlie the pathogenesis of restenosis after percutaneous transluminal angioplasty. A growth inhibitory property of overexpressed prostacyclin (PGI2) synthase (PGIS) was recently implicated in the pathological proliferation of vascular SMCs in vitro. Todaka et al. [169] demonstrated that the cDNA encoding human PGIS was transfected into endothelium-denuded rat carotid arteries after arterial balloon injury with the use of hemagglutinating virus Japan (HVJ). HVJ liposome vector complex without PGIS cDNA was used for vehicle control. The gene transfer of human PGIS expression-vector into rat carotid arteries resulted in the increased production of human PGI2 in the vascular wall, the expression of human PGIS in the developing neointima and significantly inhibition of neointimal formation after balloon injury. PGIS can be selectively augmented by cotransfecting ECs with an optimal ratio of cyclooxygenase-1 (COX-1) to PGIS. Combined COX-1 and PGIS gene transfer has the potential for therapeutic augmentation of prostacyclin [170]. PGIS gene transfer accelerated re-endothelialization and attenuated neointimal formation after stent implantation in atheromatous rabbit arteries, at least in part via increased production of VEGF protein [171].

\section{VEGF gene}

The VEGF gene has been extensively studied and used to promote revascularization and re-endothelialization by stimulating endothelial progenitor cell migration and maturation $[199,200]$. Thus, it has attracted attention as a DES candidate for its ability to promote endothelial regeneration while reducing in-stent neointimal areas in animal models [124]. Despite promising results with local delivery of the VEGF to the site of vascular injury, a recently conducted experimental study of VEGF-eluting stents failed to demonstrate a beneficial effect on endothelialization or on intimal hyperplasia. These VEGF-eluting stents did not accelerate endothelization or inhibit restenosis, but they did reduce the stent thrombosis rate, which may make them less thrombogenic [200]. Accelerated endothelialization via local delivery of endothelial specific growth factors could constitute an attractive alternative to direct antiproliferative strategies. Paul et al. [201] reported the development of a nanobiohybrid hydrogel-based endovascular stent device capable of preventing post-angioplasty ISR by promoting significant vascular endothelial recovery in a site-specific manner. The hydrogel is comprised of fibrin matrices assembled layer-by-layer (LbL) on the stent surface with alternate layers carrying endosomolytic Tat peptide/DNA nanoparticles or nanoparticles hybridized to polyacrylic acid (PAA) wrapped single-walled carbon nanotubes (nanoparticle-CNT). Here, the hydrogel works as a reservoir to carry, protect, and simultaneously deliver pro-angiogenic, VEGF and angiopoietin-1 (Ang1) gene-carrying nanoparticles to the target site. In vitro results demonstrated that CNTs incorporated in the hydrogel layers play a major role in tuning the bioactivity of the stent. In addition, the developed stent formulation can significantly reduce the loss of therapeutics while traversing through the vessel and during deployment. In vivo experiments in balloon-injured canine femoral artery demonstrated that the NCS $(+)$ group carrying nanoparticle (VEGF + Ang1) was able to significantly enhance re-endothelialization of the injured artery compared to control NCS (-) carrying nanoparticle (Null) and BMS groups. The NCS $(+)$ group also demonstrated attenuated stenosis $(18.5 \pm 9.03 \%$ vs. $39.56 \pm 13.8$ vs. $45.34 \pm 8.3 \% ; P<0.05)$ and reduced neointima formation $\left(1.53 \pm 0.36 \mathrm{~mm}^{2}\right.$ vs. $2.51 \pm 0.27 \mathrm{~mm}^{2}$ vs. $2.66 \pm$ $\left.0.14 \mathrm{~mm}^{2} ; P<0.05\right)$ by angiography and histomorphometric analysis. These data collectively imply that this new technology can be useful for stents and other biomedical devices by facilitating the controlled delivery of multiple biotherapeutics. 
The early release of the VEGF gene might promote re-endothelialization, whereas the slow release of paclitaxel may suppress SMC proliferation. In an attempt to combine gene therapy and DES drug delivery for the effective inhibition of SMC proliferation while simultaneously promoting re-endothelialization and repair, Yang et al. [202] have developed a stent coated with bi-layered PLGA nanoparticles containing $\mathrm{VEGF}_{165}$ DNA plasmid in the outer layer and paclitaxel in the inner core. These BL-PLGA NPs were then coated to laser beam pre-treated BMSs with an automatic spray machine. Using Fc plasmid as a reporter gene, they observed that $\mathrm{Fc}$ /paclitaxel nanoparticles successfully expressed Fc protein but did not show cytotoxicity or antiproliferative effects during the first 7 days in cell culture (Figure 7). In contrast, paclitaxel nanoparticles demonstrated strong antiproliferative effects starting from day 1 in culture, suggesting the sequential release of gene and paclitaxel from the bi-layered PLGA nanoparticles. In vivo effects of the treated stent were assessed in mini-swines. The implantation of GFP/paclitaxel nanoparticle-coated stents revealed efficient local GFP gene transfection at day 7. VEGF/paclitaxel nanoparticle-coated stents demonstrated complete re-endothelialization and significantly suppressed ISR after 1 month compared to commercial DESs (Figure 8 ). These data suggest that the VEGF/paclitaxel nanoparticle-coated stents promote early endothelial healing while inhibiting SMC proliferation through the sequential release of the VEGF gene and paclitaxel. The VEGF/PTX NPs were successfully coated using spray-coating technology on metal coronary stents that were pre-treated to have a nonporous surface. In vitro experiments and in vivo animal studies both confirmed that the system could promote early endothelial healing and inhibit SMC proliferation via the sequential release of selected genes and drugs. The experimental studies of nanoparticle GESs for the prevention and treatment of coronary restenosis are shown in Table 2.

Table 2. Experimental studies of nanoparticle gene-eluting stents for coronary restenosis

\begin{tabular}{|c|c|c|c|}
\hline Gene & Nanocarrier system & Finding & Reference \\
\hline Akt1 siRNA & Hyaluronic acid (HA)-coated stent & $\begin{array}{l}\text { Akt1 was released from the stent and suppressed the } \\
\text { growth of the SMCs at the peri-stent implantation area; } \\
\text { prevention of restenosis in the post-implantation phase } \\
\text { in the rabbit balloon-injured external iliac artery }\end{array}$ & $\begin{array}{l}\text { Che et al. } \\
\text { [197] }\end{array}$ \\
\hline $\begin{array}{l}\text { Anti-MCP1 } \\
\text { (anti-CCL2) }\end{array}$ & Anti-MCP 1 gene-eluting stents & $\begin{array}{l}\text { Attenuated stent-associated monocyte infiltration and } \\
\text { neointima formation after one month in rabbits; } \\
\text { long-term inhibitory effects on neointima formation at } \\
1,3 \text {, and } 6 \text { months in monkeys }\end{array}$ & $\begin{array}{l}\text { Egashira } \\
\text { et al. [179] }\end{array}$ \\
\hline $\begin{array}{l}\text { Chi- } \\
\text { tosan-plasmid } \\
\text { DNA }\end{array}$ & $\begin{array}{l}\text { Stents coated with dodecylated chi- } \\
\text { tosan-plasmid DNA nanoparticles } \\
\text { (DCDNPs) }\end{array}$ & $\begin{array}{l}\text { Reporter gene activity was observed in the region of } \\
\text { the artery in contact with the DCDNP stents in animals }\end{array}$ & $\begin{array}{l}\text { Zhu et al. } \\
\text { [87] }\end{array}$ \\
\hline $\begin{array}{l}\text { pE-NTPdase } \\
\text { (ENTPD) }\end{array}$ & $\begin{array}{l}\text { pE-NTPDase stent (cationic gela- } \\
\text { tin-coated stents) }\end{array}$ & $\begin{array}{l}\text { Increased E-NTPDase mRNA levels and NTPDase } \\
\text { activity; inhibited subacute in-stent thrombosis, neoin- } \\
\text { timal hyperplasia and inflammation in rabbit femoral } \\
\text { arteries }\end{array}$ & $\begin{array}{l}\text { Takemoto } \\
\text { et al. [190] }\end{array}$ \\
\hline eNOS (NOS3) & Adenovirus gene-eluting stent & $\begin{array}{l}\text { Enhanced endothelial regeneration and reduction in } \\
\text { neointimal formation; prevented ISR while simulta- } \\
\text { neously reduced the risk of stent thrombosis }\end{array}$ & $\begin{array}{l}\text { Sharif et } \\
\text { al. [119] }\end{array}$ \\
\hline eNOS $\beta$-Gal & $\begin{array}{l}\text { pDNA complexed with lipofectin } \\
\text { (1:1 mixture of DOTMA and DOPE) } \\
\text { to form lipoplexes; BiodivYsio HI } \\
\text { matrix PC-coated premounted stents }\end{array}$ & $\begin{array}{l}\text { Acceleration of re-endothelialization but no reduction } \\
\text { in neointimal formation (i.e., does not reduce resteno- } \\
\text { sis); prolonged and localized gene expression in rabbit } \\
\text { iliac artery model with balloon denudation of endo- } \\
\text { thelium or normocholesterolemic and hypercholester- } \\
\text { olemic rabbits }\end{array}$ & $\begin{array}{l}\text { Sharif et } \\
\text { al. [178] }\end{array}$ \\
\hline eNOS (NOS3) & $\begin{array}{l}\text { Plasmid-mediated gene delivery } \\
\text { from lipopolyplex-embedded stents }\end{array}$ & $\begin{array}{l}\text { A potent non-viral gene vector encoding for eNOS } \\
\text { coated onto a stent can inhibit restenosis through the } \\
\text { inhibition of SMC growth and the promotion of a } \\
\text { healthy endothelium }\end{array}$ & $\begin{array}{l}\text { Brito et } \\
\text { al. [189] }\end{array}$ \\
\hline GFP & $\begin{array}{l}\text { DOTAP-PbAE-pDNA lipopolyplex- } \\
\text { es; stents coated with type B gelatin } \\
\text { containing dispersed lipopolyplexes }\end{array}$ & $\begin{array}{l}\text { Successful immobilization of LPP onto stents using } \\
\text { gelatin; high cellular uptake and transfection efficiency } \\
\text { human aortic SMCs and endothelial cells, and in rabbit } \\
\text { iliac artery restenosis model with balloon denudation } \\
\text { of endothelium; however, poorly sustained LPP deliv- } \\
\text { ery in vivo due to rapid dissolution of gelatin coating }\end{array}$ & $\begin{array}{l}\text { Brito et al. } \\
{[13]}\end{array}$ \\
\hline GFP & $\begin{array}{l}\text { Cationic pDNA/PEI polyplexes; } \\
\text { stents coated with dopa- } \\
\text { mine-derivatized hyaluronic acid }\end{array}$ & $\begin{array}{l}\text { Successful deposition of DNA/PEI polyplexes onto } \\
\text { HA-DA-coated stents via electrostatic assembly; sus- } \\
\text { tained and controlled pDNA release; high gene trans- }\end{array}$ & $\begin{array}{l}\text { Kim et al. } \\
{[122]}\end{array}$ \\
\hline
\end{tabular}


(HA-DA); pDNA/PEI polyplexes ionically adsorbed onto stent surface

GFP luciferase iNOS

GFP PLGA-coated stents

GFP

GFP

GFP

GFP

GFP

VEGF2

(VEGFC)

VEGF

Angiopoietin-1

VEGF

paclitaxel
HL-modified adenovirus;

PABT/PEI(PDT)-treated steel stents; covalent attachment of HL-modified Ad vectors to the PABT/PEI(PDT)-treated metal surfaces via HL cross-linker

pDNA; stents coated with collagen conjugated to anti-pDNA antibody via SPDP pDNA/ denatured collagen

pDNA; stents coated with PAA-BP conjugated to anti-pDNA antibody via SPDP

Adenovirus/ stents coated with denatured collagen-PLGA coating conjugated to antiadenoviral antibodies

Adenovirus; stents coated with polylactide (PLA)-based nanoparticles conjugated to Ad-binding proteins

Gene-eluting stent of naked plasmid DNA encoding for hVEGF-2

Stent carrying endosomolytic Tat peptide/DNA nanoparticles or nanoparticles hybridized to polyacrylic acid (PAA) wrapped single-walled carbon nanotubes (nanoparticle-CNT)

Stent coated with bi-layered PLGA nanoparticles containing VEGF plasmid in the outer layer and paclitaxel in the inner core fection efficiency and effective biocompatibility in

COS-7 cells

Successful immobilization of adenovirus onto stents

using a 3-component gene vector binding complex:

PABT, PEI(PDT), HL; controlled and sustained release

of Ad via hydrolyzable HL; localized transgene ex-

pression in rat aortic SMCs (A10) and in rat carotid

stent angioplasty model; increase in nitric oxide pro-

duction; inhibition of restenosis

Successful arterial transfection using DNA-eluting

stent in a pig stent angioplasty model

High efficiency and site-specific gene delivery in rat

aortic SMCs (A10) and in a rabbit carotid artery stent model

Denatured collagen incorporated into pDNA-stent coating increases the level of gene expression in rat arterial SMCs (A10) and in a porcine coronary artery stent model

High localization and efficient gene delivery in pig arterial SMCs

Efficient and highly localized gene delivery/ rat arterial SMCs (A10)/ porcine coronary artery stent model

Increased gene transduction via coxsackie-adenovirus receptor (CAR)-independent cellular uptake of $\mathrm{Ad}$ vector in rat aortic SMCs (A10), bovine aortic endothelial cells (BAEC), and murine endothelioma cells (H5V) Acceleration of reendothelialization, prevention of restenosis

Fishbein

et al. [123]

Klugherz et al. [177]

Jin et al.

[180]

Perlstein

et al. [181]

Wang et

al. [182]

Klugherz

et al. [187]

Chorny et

al. [188] in balloon-injured canine femoral artery

Demonstrated complete re-endothelialization and significantly suppressed in-stent restenosis after 1
Enhanced re-endothelialization of injured artery, attenuated stenosis and prevented neointima formation Yang et al. [202]

Walter et

al. [124]

Paul et al. [201] month in mini-swines

Abbreviations: Anti-MCP 1, antimonocyte chemoattractant protein 1; DOPE, dioleoyl phosphatidylethanolamine; DOTAP, cationic 1-oleoyl-2-[6-[(7-nitro-2-1,3-benzoxadiazol-4yl)amino] hexanoyl]-3-trimethylammonium propane; DOTMA cationic lipid, N-[1-(2,3- dioleyloxy)propyl]-N,N,N-trimethylammonium chloride; eNOS, endothelial nitric oxide synthase; ENTPD, ectonucleoside triphosphate diphosphohydrolase; GFP, green fluorescent protein; iNOS, inducible nitric oxide synthase; ISR, in-stent restenosis; LPP, liposomes or lipopolyplexes; PABT, polyallylamine bisphosphonate with latent thiol groups; PEI(PDT), polyethyleneimine with pyridyldithio groups; PLA, Poly(L-lactic acid); PLGA, poly(D,L-lactide-co-glycolide; SMC, smooth muscle cells; SPDP, N- succinimidyl 3-(2-pyridyldithio)propionate; VEGF2, vascular endothelial growth factor 2; VEGFC, vascular endothelial growth factor $\mathrm{C}$ 
A
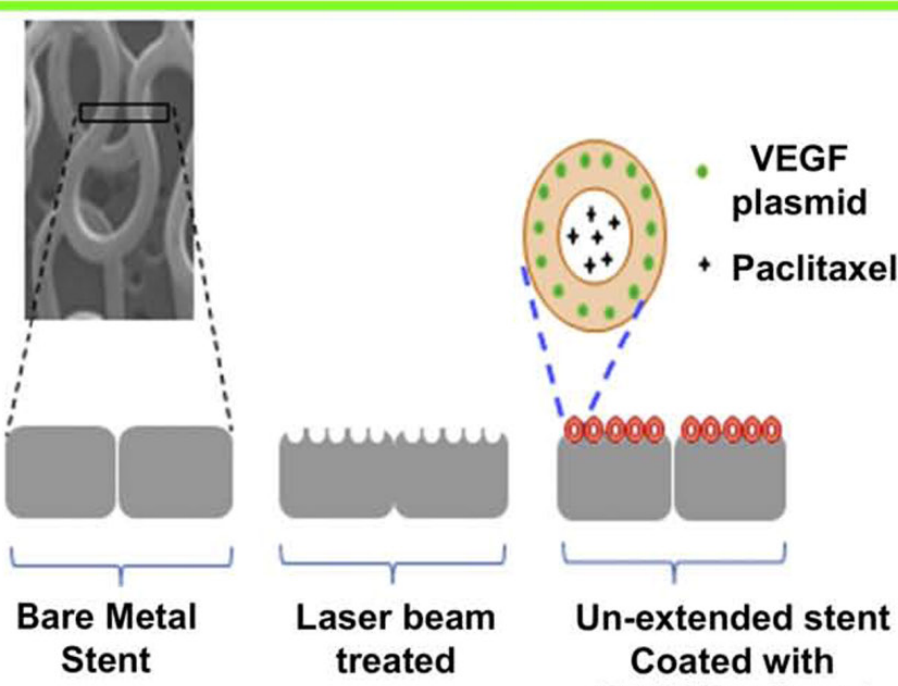

\section{Un-extended stent}

Coated with

VEGF/Paclitaxel

PLGA

Nanoparticles

B

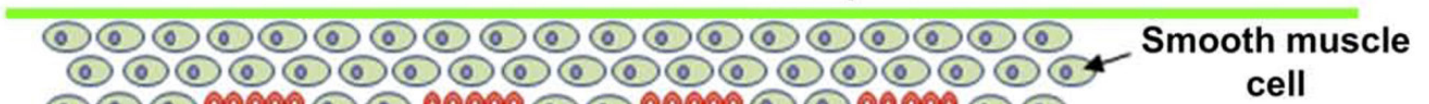
100000
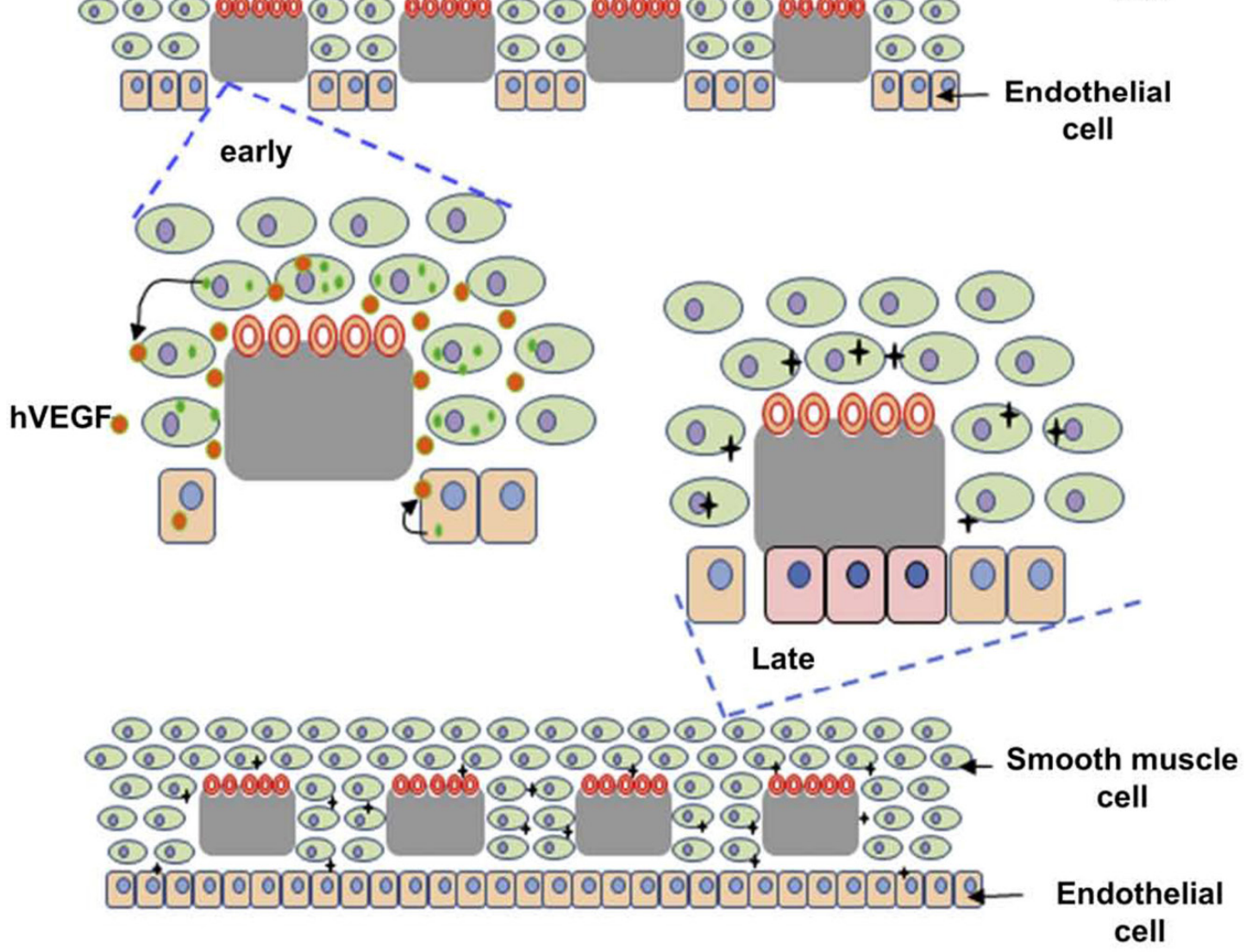

Figure 7. Schematic diagrams of material design and function hypothesis. (A), the structure of bi-layered VEGF/PTX NPs and procedures of stent coating. The bare metal stents were pre-treated with laser beam which generates nano pores to increase the coating amount and stability. (B), assumed sequential release of VEGF/PTX and the mechanism of their function. The sequential releasing pattern allows rapid re-endothelialization in the early days and later inhibition of smooth muscle cell proliferation. Reproduced with permission from Elsevier Ltd. 

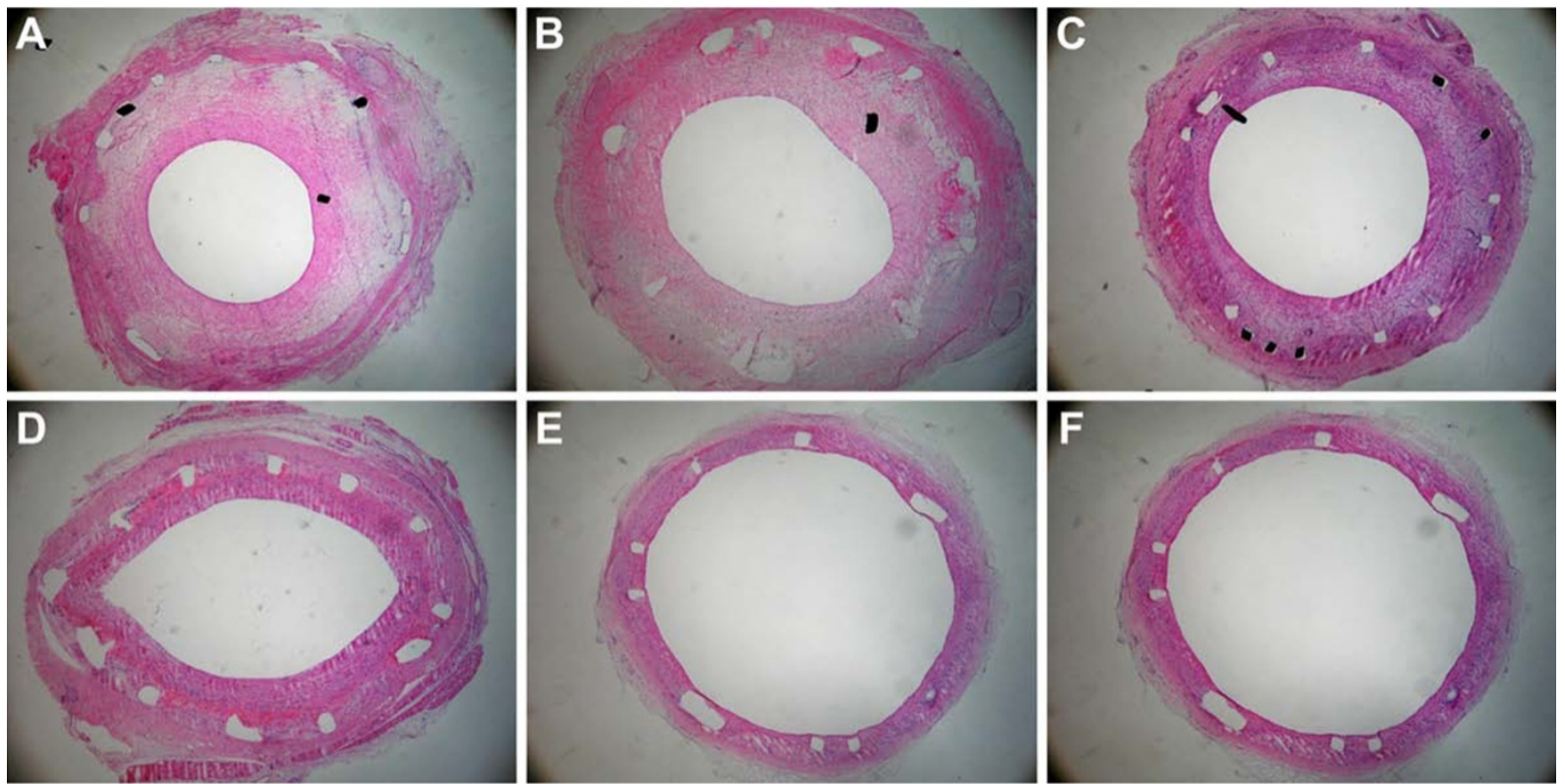

Figure 8. Representative images of $\mathrm{H} \& \mathrm{E}$ staining of cross-sections 28 days after implantation. (A), bare stent; (B), blank NPs coated stent; (C), PTX NPs coated stent; (D), TAXUS ${ }^{\circledR}$ stent; (E), VEGF NPs coated stent; (F), VEGF/PTX NPs coated stent. $(\times 40)$. Reproduced with permission from Elsevier Ltd.

\section{Conclusion and future outlook}

Following the first generation of sirolimus- and paclitaxel-eluting stents, a variety of new stent designs, coatings and locally delivered agents are emerging and most likely will become available in a few years' time. The development of DESs has been pioneered through a combination of an enhanced understanding of the biology of restenosis, the selection of drugs that target 1 or more pathways in the restenotic process, controlled-release drug delivery strategies, and the use of the stent as a delivery platform. An ideal DES polymer should be non-thrombotic, non-inflammatory, and non-toxic and should facilitate vascular healing by accelerating re-endothelialization [202]. The ideal drug to prevent restenosis must have antiproliferative and anti-migratory effects on SMCs but must also enhance re-endothelialization to prevent late thrombosis. Additionally, it should effectively inhibit the anti-inflammatory response after balloon-induced arterial injury. There is a need to develop an alternative to stents and DESs for the treatment of CAD. In the present review paper, we have evaluated the current research in the field of nanoparticle drug- or gene-eluting stents. Future work should focus on creating novel delivery systems that have less cytotoxic effects. The cytostatic drugs currently being used may not be the best option for the treatment of this disorder, as they do not promote endothelial growth. The work performed in the field of active targeting has produced a number of cell-specific targeting ligands that would enhance the delivery and retention of the nanoparticles in the reste- notic lesion, resulting in increased efficacy of the therapeutic agent. Future studies should focus on creating biocompatible nanoparticles with targeting moieties to allow for increased tissue-specific delivery and cellular uptake with limited toxicity upon systemic administration [203]. Future research is also mandatory to further clarify whether these patients should be treated with the same DES, with a different DES or with increased doses. Further improvements, including expansion of drug-loading capacity, coatings with programmable pharmacokinetic capacity and the discovery of new drugs may in the future further enhance the efficacy and safety of these stents.

\section{Acknowledgments}

This study was supported by the National Natural Science Foundation of China (No: 30960130) and the Science Foundation of Guangxi Returned Overseas Scholars (No: 0991004).

\section{Competing Interests}

The authors have declared that no competing interest exists.

\section{References}

1. Deaton C, Froelicher ES, Wu LH, Ho C, et al. The global burden of cardiovascular disease. J Cardiovasc Nurs. 2011;26(4 Suppl):S5-S14.

2. [Internet] WHO. World Health Statistics 2008. http://www.who.int/whosis/whostat/2008/en/index.html

3. Kavanagh CA, Rochev YA, Gallagher WM, et al. Local drug delivery in restenosis injury: thermoresponsive co-polymers as potential drug delivery systems. Pharmacol Ther. 2004;102:1-15.

4. Hamon M, Lecluse E, Monassier JP, et al. Pharmacological approaches to the prevention of restenosis after coronary angioplasty. Drugs Aging. 1998; 13:291-301.

5. Burta HM, Hunter WL. Drug-eluting stents: a multidisciplinary success story. Adv Drug Deliv Rev. 2006;58:350-7. 
6. Panyam J, Labbhasetwar V. Biodegradable nanoparticles for drug and gene delivery to cells and tissue. Adv Drug Deliv Rev. 2003;55:329-47.

7. Virmani R, Farb A. Pathology of in-stent restenosis. Curr Opin Lipidol. 1999;10:499-506.

8. Tepe G, Wendel HP, Khorchidi S, et al. Thrombogenicity of various endovascular stent types: an in vitro evaluation. J Vasc Interv Radiol. 2002:13:1029-35.

9. Hofma SH, van der Giessen WJ, van Dalen BM, et al. Indication of long-term endothelial dysfunction after sirolimus-eluting stent implantation. Eur Heart J. 2006;27:166-70.

10. van der Hoeven BL, Pires NM, Warda HM, et al. Drug-eluting stents: results, promises and problems. Int J Cardiol. 2005;99:9-17.

11. Tan A, Farhatnia Y, de Mel A, et al. Inception to actualization: next generation coronary stent coatings incorporating nanotechnology. J Biotechnol. 2013;164:151-70.

12. Berliner JA, Navab M, Fogelman AM, et al. Atherosclerosis: basic mechanisms. Oxidation, inflammation, and genetics. Circulation. 1995;91:2488-96.

13. Brito LA, Chandrasekhar S, Little SR, et al. In vitro and in vivo studies of local arterial gene delivery and transfection using lipopolyplexes-embedded stents. J Biomed Mater Res A. 2010;93:325-36.

14. Indolfi C, Coppola C, Torella D, et al. Gene therapy for restenosis after balloon angioplasty and stenting. Cardiol Rev. 1999;7:324-31.

15. Indolfi C, Torella D, Coppola C, et al. Rat carotid artery dilation by PTCA balloon catheter induces neointima formation in presence of IEL rupture. Am J Physiol Heart Circ Physiol. 2002;283:H760-H767.

16. Glagov S, Weisenberg E, Zarins CK, et al. Compensatory enlargement of human atherosclerotic coronary arteries. N Engl J Med. 1987;316:1371-5.

17. Mintz GS, Popma JJ, Pichard AD, et al. Arterial remodeling after coronary angioplasty: a serial intravascular ultrasound study. Circulation. 1996;94:35-43.

18. Dangas G, Fuster V. Management of restenosis after coronary intervention. Am Heart J. 1996 ;132(2 Pt 1):428-36.

19. Teirstein PS, Massullo V, Jani S, et al. Catheter-based radiotherapy to inhibit restenosis after coronary stenting. N Engl J Med. 1997;336:1697-703.

20. Mehran R, Dangas G, Abizaid AS, et al. Angiographic patterns of in-stent restenosis: classification and implications for long-term outcome. Circulation. 1999;100:1872-8.

21. Scott NA. Restenosis following implantation of bare metal coronary stents: Pathophysiology and pathways involved in the vascular response to injury. Adv Drug Deliv Rev. 2006;58:358-76.

22. Hoffmann R, Mintz GS, Dussaillant GR, et al. Patterns and mechanisms of in-stent restenosis. A serial intravascular ultrasound study. Circulation. 1996;94:1247-54

23. Nakatani M, Takeyama $Y$, Shibata $M$, et al. Mechanisms of restenosis after coronary intervention: difference between plain old balloon angioplasty and stenting. Cardiovasc Pathol. 2003;12:40-8.

24. Miano JM, Vlasic N, Tota RR, et al. Localization of Fos and Jun proteins in rat aortic smooth muscle cells after vascular injury. Am J Pathol. 1993:142:715-24.

25. Farb A, Weber DK, Kolodgie FD, et al. Morphological predictors of restenosis after coronary stenting in humans. Circulation. 2002;105:2974-80.

26. Farb A, Kolodgie FD, Hwang JY, et al. Extracellular matrix changes in stented human coronary arteries. Circulation. 2004;110:940-7.

27. Welt FG, Rogers C. Inflammation and restenosis in the stent era. Arterioscler Thromb Vasc Biol. 2002;22:1769-76.

28. Riessen R, Wight TN, Pastore C, et al. Distribution of hyaluronan during extracellular matrix remodeling in human restenotic arteries and balloon-injured rat carotid arteries. Circulation. 1996;93:1141-7.

29. Costa MA, Simon DI. Molecular basis of restenosis and drug-eluting stents. Circulation. 2005;111:2257-73.

30. Grube E, Gerckens U, Müller R, et al. Drug eluting stents: initial experiences. Z Kardiol. 2002;91(Suppl 3):44-8.

31. Voisard R, Dartsch PC, Seitzer U, et al. The in-vitro effect of antineoplastic agents on proliferative activity and cytoskeletal components of plaque-derived smooth-muscle cells from human coronary arteries. Coron Artery Dis. 1993:4:935-42

32. Voisard R, Seitzer U, Baur R, et al. A prescreening system for potential antiproliferative agents: implications for local treatment strategies of postangioplasty restenosis. Int J Cardiol. 1995;51:15-28.

33. Marx SO, Jayaraman T, Go LO, et al. Rapamycin-FKBP inhibits cell cycle regulators of proliferation in vascular smooth muscle cells. Circ Res. 1995;76:412-7.

34. Sollott SJ, Cheng L, Pauly RR, et al. Taxol inhibits neointimal smooth muscle cell accumulation after angioplasty in the rat. J Clin Invest. 1995;95:1869-76.

35. Charles R, Sandirasegarane L, Yun J, et al. Ceramide-coated balloon catheters limit neointimal hyperplasia after stretch injury in carotid arteries. Circ Res. 2000;87:282-8.

36. Tanabe Y, Ito E, Nakagawa I, et al. Effect of cilostazol on restenosis after coronary angioplasty and stenting in comparison to conventional coronary artery stenting with ticlopidine. Int J Cardiol. 2001;78:285-91.

37. Ahrens I, Peter K, Bode C. Use of GPIIb/IIIa inhibitors in cardiovascular medicine. Expert Rev Cardiovasc Ther. 2003;1:233-42.

38. Danenberg HD, Fishbein I, Gao J, et al. Macrophage depletion by clodronate-containing liposomes reduces neointimal formation after balloon injury in rats and rabbits. Circulation. 2002;106:599-605.
39. Danenberg HD, Fishbein I, Epstein H, et al. Systemic depletion of macrophages by liposomal bisphosphonates reduces neointimal formation following balloon-injury in the rat carotid artery. J Cardiovasc Pharmacol. 2003;42:671-9.

40. Banai S, Wolf Y, Golomb G, et al. PDGF-receptor tyrosine kinase blocker AG1295 selectively attenuates smooth muscle cell growth in vitro and reduces neointimal formation after balloon angioplasty in swine. Circulation. 1998;97:1960-9.

41. Banai S, Chorny M, Gertz SD, et al. Locally delivered nanoencapsulated tyrphostin (AGL-2043) reduces neointima formation in balloon-injured rat carotid and stented porcine coronary arteries. Biomaterials. 2005;26:451-61.

42. New G, Moses JW, Roubin GS, et al. Estrogen-eluting, phosphorylcholine-coated stent implantation is associated with reduced neointimal formation but no delay in vascular repair in a porcine coronary model. Catheter Cardiovasc Interv. 2002;57:266-71.

43. Takagi T, Akasaka T, Yamamuro A, et al. Troglitazone reduces neointimal tissue proliferation after coronary stent implantation in patients with non-insulin dependent diabetes mellitus: a serial intravascular ultrasound study. J Am Coll Cardiol. 2000;36:1529-35.

44. Ishiwata S, Verheye S, Robinson KA, et al. Inhibition of neointima formation by tranilast in pig coronary arteries after balloon angioplasty and stent implantation. J Am Coll Cardiol. 2000;35:1331-7.

45. Peters S, Götting B, Trümmel M, et al. Valsartan for prevention of restenosis after stenting of type B2/C lesions: the VAL-PREST trial. J Invasive Cardiol. 2001;13:93-7.

46. Walter DH, Schächinger V, Elsner M, et al. Effect of statin therapy on restenosis after coronary stent implantation. Am J Cardiol. 2000;85:962-8.

47. Dangas G, Iakovou I. The end of systemic anticoagulation therapy for restenosis prevention. J Invasive Cardiol. 2001;13:729-31.

48. Marx SO, Marks AR. Bench to bedside: the development of rapamycin and its application to stent restenosis. Circulation. 2001;104:852-5.

49. Gingras AC, Raught B, Sonenberg N. mTOR signaling to translation. Curr Top Microbiol Immunol. 2004;279:169-97.

50. Sousa JE, Costa MA, Abizaid AC, et al. Sustained suppression of neointimal proliferation by sirolimus-eluting stents: one-year angiographic and intravascular ultrasound follow-up. Circulation. 2001;104:2007-11.

51. Aoki J, Abizaid AC, Serruys PW, et al. Evaluation of four-year coronary artery response after sirolimus-eluting stent implantation using serial quantitative intravascular ultrasound and computer-assisted grayscale value analysis for plaque composition in event-free patients. J Am Coll Cardiol. 2005;46:1670-6.

52. Serruys PW, Garg S, Abizaid A, et al. A randomised comparison of novolimus-eluting and zotarolimus-eluting coronary stents: 9-month follow-up results of the EXCELLA II study. EuroIntervention. 2010;6:195-205.

53. Schuler W, Sedrani R, Cottens S, et al. SDZ RAD, a new rapamycin derivative: pharmacological properties in vitro and in vivo. Transplantation. 1997;64:36-42.

54. Serruys PW, Ong AT, Piek JJ, et al. A randomized comparison of a durable polymer Everolimus-eluting stent with a bare metal coronary stent: The SPIRIT first trial. EuroIntervention. 2005;1:58-65.

55. Joner M, Nakazawa G, Finn AV, et al. Endothelial cell recovery between comparator polymer-based drug-eluting stents. J Am Coll Cardiol. 2008;52:333-42.

56. Haraguchi G, Pruitt S, Brodeur A, et al. Increased expression of eNOS by Endeavor zotarolimus-eluting stents compared to other DES in porcine coronary artery implants. Am J Cardiol. 2006:98(Suppl):32-3.

57. Ostojic M, Sagic D, Jung R, et al. The pharmacokinetics of Biolimus A9 after elution from the Nobori stent in patients with coronary artery disease: the NOBORI PK study. Catheter Cardiovasc Interv. 2008;72:901-8.

58. Ostojic MC, Perisic Z, Sagic D, et al. The pharmacokinetics of Biolimus A9 after elution from the BioMatrix II stent in patients with coronary artery disease: the Stealth PK Study. Eur J Clin Pharmacol. 2011;67:389-98.

59. Vetrovec GW, Rizik D, Williard C, et al. Sirolimus PK trial: a pharmacokinetic study of the sirolimus-eluting Bx velocity stent in patients with de novo coronary lesions. Catheter Cardiovasc Interv. 2006;67:32-7.

60. Hamilos MI, Ostojic M, Beleslin B, et al. Differential effects of drug-eluting stents on local endothelium-dependent coronary vasomotion. J Am Coll Cardiol. 2008:51:2123-9.

61. Steffel J, Latini RA, Akhmedov A, et al. Rapamycin, but not FK-506, increases endothelial tissue factor expression: implications for drug-eluting stent design. Circulation. 2005;112:2002-11

62. Morice MC, Bestehorn HP, Carrié D, et al. Direct stenting of de novo coronary stenoses with tacrolimus-eluting versus carbon-coated carbostents. The randomized JUPITER II trial. EuroIntervention. 2006;2:45-52.

63. Zollinger M, Waldmeier F, Hartmann S, et al. Pimecrolimus: absorption, distribution, metabolism, and excretion in healthy volunteers after a single oral dose and supplementary investigations in vitro. Drug Metab Dispos. 2006;34:765-74

64. Ormiston JA, Webster MW, Schwartz RS, et al. Feasibility, safety, and efficacy of a novel polymeric pimecrolimus-eluting stent: traditional pre-clinical safety end points failed to predict 6-month clinical angiographic results. JACC Cardiovasc Interv. 2009;2:1017-24.

65. Giannakakou P, Robey R, Fojo T, et al. Low concentrations of paclitaxel induce cell type-dependent p53, p21 and G1/G2 arrest instead of mitotic arrest: molecular determinants of paclitaxel-induced cytotoxicity. Oncogene. 2001;20:3806-13 
66. Lansky AJ, Costa RA, Mintz GS, et al. Non-polymer-based paclitaxel-coated coronary stents for the treatment of patients with de novo coronary lesions: angiographic follow-up of the DELIVER clinical trial. Circulation. 2004;109:1948-54.

67. Grube E, Silber S, Hauptmann KE, et al. TAXUS I: six- and twelve-month results from a randomized, double-blind trial on a slow-release paclitaxel-eluting stent for de novo coronary lesions. Circulation. 2003;107:38-42.

68. Serruys PW, Degertekin M, Tanabe K, et al. Vascular responses at proximal and distal edges of paclitaxel-eluting stents: serial intravascular ultrasound analysis from the TAXUS II trial. Circulation. 2004;109:627-33.

69. Stone GW, Ellis SG, Cox DA, et al. One-year clinical results with the slow-release, polymer-based, paclitaxel-eluting TAXUS stent: the TAXUS-IV trial. Circulation. 2004;109:1942-7.

70. Hermiller JB, Raizner A, Cannon L, et al. Outcomes with the polymer-based paclitaxel-eluting TAXUS stent in patients with diabetes mellitus: the TAXUS-IV trial. J Am Coll Cardiol. 2005;45:1172-9.

71. Weissman NJ, Ellis SG, Grube E, et al. Effect of the polymer-based, paclitaxel-eluting TAXUS Express stent on vascular tissue responses: a volumetric intravascular ultrasound integrated analysis from the TAXUS IV, V, and VI trials. Eur Heart J. 2007;28:1574-82.

72. Serruys PW, Ormiston JA, Sianos G, et al. Actinomycin-eluting stent for coronary revascularization: a randomized feasibility and safety study: the ACTION trial. J Am Coll Cardiol. 2004;44:1363-7.

73. Cato AC, Wade E. Molecular mechanisms of anti-inflammatory action of glucocorticoids. Bioessays. 1996;18:371-8.

74. Liu X, Huang Y, Hanet C, et al. Study of antirestenosis with the BiodivYsio dexamethasone-eluting stent (STRIDE): a first-in-human multicenter pilot trial. Catheter Cardiovasc Interv. 2003;60:172-9.

75. Lefer AM, Scalia R, Lefer DJ. Vascular effects of HMG CoA-reductase inhibitors (statins) unrelated to cholesterol lowering: new concepts for cardiovascular disease. Cardiovasc Res. 2001;49:281-7.

76. van der Harst $\mathrm{P}$, Groenewegen $\mathrm{HC}$, Roks AJ, et al. Rosuvastatin attenuates angiotensin II-induced neointimal formation after stent implantation in the rat. Coron Artery Dis. 2008;19:47-53.

77. Serruys PW, Onuma Y, Ormiston JA, et al. Evaluation of the second generation of a bioresorbable everolimus drug-eluting vascular scaffold for treatment of de novo coronary artery stenosis: six-month clinical and imaging outcomes. Circulation. 2010;122:2301-12.

78. Lincoff AM, Furst JG, Ellis SG, et al. Sustained local delivery of dexamethasone by a novel intravascular eluting stent to prevent restenosis in the porcine coronary injury model. J Am Coll Cardiol. 1997; 29:808-16.

79. Rajtar A, Kaluza GL, Yang Q, et al. Hydroxyapatite-coated cardiovascular stents. EuroIntervention. 2006;2:113-5

80. Remuzzi A, Mantero S, Colombo M, et al. Vascular smooth muscle cells on hyaluronic acid: culture and mechanical characterization of an engineered vascular construct. Tissue Eng. 2004;10:699-710.

81. Travis JA, Hughes MG, Wong JM, et al. Hyaluronan enhances contraction of collagen by smooth muscle cells and adventitial fibroblasts: Role of CD44 and implications for constrictive remodeling. Circ Res. 2001;88:77-83.

82. Heublein B, Evagorou EG, Rohde R, et al. Polymerized degradable hyaluronan--a platform for stent coating with inherent inhibitory effects on neointimal formation in a porcine coronary model. Int J Artif Organs. 2002;25:1166-73

83. Jensen DK, Jensen LB, Koocheki S, et al. Design of an inhalable dry powder formulation of DOTAP-modified PLGA nanoparticles loaded with siRNA. J Control Release. 2012;157:141-8.

84. Steinbach JM, Weller CE, Booth CJ, et al. Polymer nanoparticles encapsulating siRNA for treatment of HSV-2 genital infection. J Control Release. 2012;162:102-10.

85. Chorny M, Fishbein I, Yellen BB, et al. Targeting stents with local delivery of paclitaxel-loaded magnetic nanoparticles using uniform fields. Proc Natl Acad Sci USA. 2010;107:8346-51.

86. Yuan X, Shah BA, Kotadia NK, et al. The development and mechanism studies of cationic chitosan-modified biodegradable PLGA nanoparticles for efficient siRNA drug delivery. Pharm Res. 2010;27:1285-95.

87. Zhu $D$, Jin $X$, Leng $X$, et al. Local gene delivery via endovascular stents coated with dodecylated chitosan-plasmid DNAnanoparticles. Int J Nanomedicine. 2010;5:1095-102.

88. Krucoff MW, Kereiakes DJ, Petersen JL, et al. A novel bioresorbable polymer paclitaxel-eluting stent for the treatment of single and multivessel coronary disease: primary results of the COSTAR (Cobalt Chromium Stent With Antiproliferative for Restenosis) II study. Am Coll Cardiol. 2008;51:1543-52.

89. Windecker S, Serruys PW, Wandel S, et al. Biolimus-eluting stent with biodegradable polymer versus sirolimus-eluting stent with durable polymer for coronary revascularisation (LEADERS): a randomised non-inferiority trial. Lancet. 2008;372:1163-73.

90. Byrne RA, Kastrati A, Kufner S, et al. Randomized, non-inferiority trial of three limus agent-eluting stents with different polymer coatings: the Intracoronary Stenting and Angiographic Results: Test Efficacy of 3 Limus-Eluting Stents (ISAR-TEST-4) Trial. Eur Heart J. 2009;30:2441-9.

91. Tamai H, Igaki K, Kyo E, et al. Initial and 6-month results of biodegradable poly-l-lactic acid coronary stents in humans. Circulation. 2000;102:399-404.

92. Radeleff B, Thierjung H, Stampfl U, et al. Restenosis of the CYPHER-Select, TAXUS-Express, and Polyzene-F nanocoated cobalt-chromium stents in the minipig coronary artery model. Cardiovasc Intervent Radiol. 2008;31:971-80.
93. Tamburino C, La Manna A, Di Salvo ME, et al. First-in-man 1-year clinical outcomes of the Catania Coronary Stent System with Nanothin Polyzene-F in de novo native coronary artery lesions: the ATLANTA (Assessment of The LAtest Non-Thrombogenic Angioplasty stent) trial. JACC Cardiovasc Interv. 2009;2:197-204

94. La Manna A, Capodanno D, Cera M, et al. Optical coherence tomographic results at six-month follow-up evaluation of the CATANIA coronary stent system with nanothin Polyzene-F surface modification (from the Assessment of The LAtest Non-Thrombogenic Angioplasty Stent [ATLANTA] trial). Am J Cardiol. 2009;103:1551-5.

95. Khan W, Farah S, Domb AJ. Drug eluting stents: developments and current status. J Control Release. 2012;161:703-12.

96. Rogers CD. Optimal stent design for drug delivery. Rev Cardiovasc Med. 2004;5(Suppl 2):S9-S15

97. Abizaid A, Costa JR Jr. New drug-eluting stents: an overview on biodegradable and polymer-free next-generation stent systems. Circ Cardiovasc Interv. 2010;3:384-93

98. Stone GW, Teirstein PS, Meredith IT, et al. A prospective, randomized evaluation of a novel everolimus-eluting coronary stent: the PLATINUM (a Prospective, Randomized, Multicenter Trial to Assess an Everolimus-Eluting Coronary Stent System [PROMUS Element] for the Treatment of Up to Two de Novo Coronary Artery Lesions) trial. J Am Coll Cardiol. 2011;57:1700-8.

99. Kereiakes DJ, Cannon LA, Feldman RL, et al. Clinical and angiographic outcomes after treatment of de novo coronary stenoses with a novel platinum chromium thin-strut stent: primary results of the PERSEUS (Prospective Evaluation in a Randomized Trial of the Safety and Efficacy of the Use of the TAXUS Element Paclitaxel-Eluting Coronary Stent System) trial. J Am Coll Cardiol. 2010:56:264-71.

100. Capodanno D, Dipasqua F, Tamburino C. Novel drug-eluting stents in the treatment of de novo coronary lesions. Vasc Health Risk Manag. 2011;7:103-18.

101. Ormiston JA, Lefèvre T, Grube E, et al. First human use of the TAXUS Petal paclitaxel-eluting bifurcation stent. EuroIntervention. 2010;6:46-53.

102. Garg S, Serruys PW. Coronary stents: looking forward. J Am Coll Cardiol. 2010;56(10 Suppl):S43-S78.

103. Costa RA, Abizaid A, Abizaid AS, et al. Procedural and early clinical outcomes of patients with de novo coronary bifurcation lesions treated with the novel Nile PAX dedicated bifurcation polymer-free paclitaxel coated stents: results from the prospective, multicentre, non-randomised BIPAX clinical trial. EuroIntervention. 2012;7:1301-9.

104. Verheye S, Ramcharitar S, Grube E, et al. Six-month clinical and angiographic results of the STENTYS® self-apposing stent in bifurcation lesions. EuroIntervention. 2011;7:580-7.

105. Danenberg HD, Golomb G, Groothuis A, et al. Liposomal alendronate inhibits systemic innate immunity and reduces in-stent neointimal hyperplasia in rabbits. Circulation. 2003;108:2798-804.

106. Kolodgie FD, John M, Khurana C, et al. Sustained reduction of in-stent neointimal growth with the use of a novel systemic nanoparticle paclitaxel. Circulation. 2002;106:1195-8

107. Margolis J, McDonald J, Heuser R, et al. Systemic nanoparticle paclitaxel (nab-paclitaxel) for in-stent restenosis I (SNAPIST-I): a first-in-human safety and dose-finding study. Clin Cardiol. 2007;30:165-70.

108. Joner M, Morimoto K, Kasukawa H, et al. Site-specific targeting of nanoparticle prednisolone reduces in-stent restenosis in a rabbit model of established atheroma. Arterioscler Thromb Vasc Biol. 2008;28:1960-6.

109. Chan JM, Rhee JW, Drum CL, et al. In vivo prevention of arterial restenosis with paclitaxel-encapsulated targeted lipid-polymeric nanoparticles. Proc Natl Acad Sci U S A. 2011;108:19347-52.

110. Lanza GM, Yu X, Winter PM, et al. Targeted antiproliferative drug delivery to vascular smooth muscle cells with a magnetic resonance imaging nanoparticle contrast agent: implications for rational therapy of restenosis. Circulation. 2002;106:2842-7.

111. Ceylan H, Tekinay AB, Guler MO. Selective adhesion and growth of vascular endothelial cells on bioactive peptide nanofiber functionalized stainless steel surface. Biomaterials. 2011;32:8797-805.

112. Polyak B, Fishbein I, Chorny M, et al. High field gradient targeting of magnetic nanoparticle-loaded endothelial cells to the surfaces of steel stents. Proc Natl Acad Sci U S A. 2008;105:698-703.

113. Masuda S, Nakano K, Funakoshi K, et al. Imatinib mesylate-incorporated nanoparticle-eluting stent attenuates in-stent neointimal formation in porcine coronary arteries. J Atheroscler Thromb. 2011;18:1043-53.

114. Bhargava B, Reddy NK, Karthikeyan G, et al. A novel paclitaxel-eluting porous carbon-carbon nanoparticle coated, nonpolymeric cobalt-chromium stent: evaluation in a porcine model. Catheter Cardiovasc Interv. 2006;67:698-702

115. Tsukie N, Nakano K, Matoba T, et al. Pitavastatin-incorporated nanoparticle-eluting stents attenuate in-stent stenosis without delayed endothelial healing effects in a porcine coronary artery model. J Atheroscler Thromb. 2013;20:32-45.

116. Luderer $\mathrm{F}$, Löbler $\mathrm{M}$, Rohm HW, et al. Biodegradable sirolimus-loaded poly(lactide) nanoparticles as drug delivery system for the prevention of in-stentrestenosis in coronary stent application. J Biomater Appl. 2011;25:851-75.

117. Räthel T, Mannell H, Pircher J, et al. Magnetic stents retain nanoparticle-bound antirestenotic drugs transported by lipid microbubbles. Pharm Res. 2012;29:1295-307. 
118. Acharya G, Lee $\mathrm{CH}$, Lee Y. Optimization of cardiovascular stent against restenosis: factorial design-based statistical analysis of polymer coating conditions. PLoS One. 2012;7:e43100.

119. Sharif F, Hynes SO, Cooney R, et al. Gene-eluting stents: adenovirus-mediated delivery of eNOS to the blood vessel wall accelerates re-endothelialization and inhibits restenosis. Mol Ther. 2008;16:1674-80.

120. Muhs A, Heublein B, Schletter J, et al. Preclinical evaluation of inducible nitric oxide synthase lipoplex gene therapy for inhibition of stent-induced vascular neointimal lesion formation. Hum Gene Ther. 2003;14:375-83.

121. Wang K, Kessler PD, Zhou Z, et al. Local adenoviral-mediated inducible nitric oxide synthase gene transfer inhibits neointimal formation in the porcine coronary stented model. Mol Ther. 2003;7(5 Pt 1):597-603.

122. Kim TG, Lee Y, Park TG. Controlled gene-eluting metal stent fabricated by bio-inspired surface modification with hyaluronic acid and deposition of DNA/PEI polyplexes. Int J Pharm. 2010;384:181-8.

123. Fishbein I, Alferiev I, Bakay M, et al. Local delivery of gene vectors from bare-metal stents by use of a biodegradable synthetic complex inhibits in-stent restenosis in rat carotid arteries. Circulation. 2008;117:2096-103.

124. Walter DH, Cejna M, Diaz-Sandoval L, et al. Local gene transfer of phVEGF-2 plasmid by gene-eluting stents: an alternative strategy for inhibition of restenosis. Circulation. 2004:110:36-45.

125. Fishbein I, Alferiev IS, Nyanguile O, et al. Bisphosphonate-mediated gene vector delivery from the metal surfaces of stents. Proc Natl Acad Sci U S A. 2006;103:159-64.

126. Sharif F, Daly K, Crowley J, et al. Current status of catheter- and stent-based gene therapy. Cardiovasc Res. 2004;64:208-16.

127. Jin X, Mei L, Song C, et al. Immobilization of plasmid DNA on an anti-DNA antibody modified coronary stent for intravascular site-specific gene therapy. J Gene Med. 2008;10:421-9.

128. Bengali Z, Rea JC, Shea LD. Gene expression and internalization following vector adsorption to immobilized proteins: dependence on protein identity and density. J Gene Med. 2007;9:668-78.

129. Rutanen J, Markkanen J, Ylä-Herttuala S. Gene therapy for restenosis: current status. Drugs. 2002;62:1575-85.

130. Guzman RJ, Hirschowitz EA, Brody SL, et al. In vivo suppression of injury-induced vascular smooth muscle cell accumulation using adenovirus-mediated transfer of the herpes simplex virus thymidine kinase gene. Proc Natl Acad Sci USA. 1994;91:10732-6.

131. Ogata H, Mishio M, Luo XX, et al. Significance of elevated cytochrome aa3 in a state of endotoxemia in dogs. Resuscitation. 1996;33:63-8.

132. Ohno T, Gordon D, San H, et al. Gene therapy for vascular smooth muscle cell proliferation after arterial injury. Science. 1994;265:781-4.

133. Simari RD, San H, Rekhter M, et al. Regulation of cellular proliferation and intimal formation following balloon injury in atherosclerotic rabbit arteries. J Clin Invest. 1996;98:225-35.

134. Harrell RL, Rajanayagam S, Doanes AM, et al. Inhibition of vascular smooth muscle cell proliferation and neointimal accumulation by adenovirus-mediated gene transfer of cytosine deaminase. Circulation. 1997;96:621-7.

135. Mano T, Luo Z, Suhara T, et al. Expression of wild-type and noncleavable fas ligand by tetracycline-regulated adenoviral vectors to limit intimal hyperplasia in vascular lesions. Hum Gene Ther. 2000;11:1625-35.

136. Morishita R, Gibbons GH, Ellison KE, et al. Evidence for direct local effect of angiotensin in vascular hypertrophy. In vivo gene transfer of angiotensin converting enzyme. J Clin Invest. 1994;94:978-84.

137. Chen D, Krasinski K, Sylvester A, et al. Downregulation of cyclin-dependent kinase 2 activity and cyclin A promoter activity in vascular smooth muscle cells by p27(KIP1), an inhibitor of neointima formation in the rat carotid artery. J Clin Invest. 1997;99:2334-41.

138. Yonemitsu Y, Kaneda Y, Tanaka S, et al. Transfer of wild-type p53 gene effectively inhibits vascular smooth muscle cell proliferation in vitro and in vivo. Circ Res. 1998;82:147-56.

139. Scheinman M, Ascher E, Kallakuri S, et al. P53 gene transfer to the injured rat carotid artery promotes apoptosis. Surgery. 1999;126:863-8.

140. Tanner FC, Boehm M, Akyürek LM, et al. Differential effects of the cyclin-dependent kinase inhibitors p27(Kip1), p21(Cip1), and p16(Ink4) on vascular smooth muscle cell proliferation. Circulation. 2000;101:2022-5.

141. Tsui LV, Camrud A, Mondesire J, et al. p27-p16 fusion gene inhibits angioplasty-induced neointimal hyperplasia and coronary artery occlusion. Circ Res. 2001;89:323-8.

142. Chang MW, Barr E, Seltzer J, et al. Cytostatic gene therapy for vascular proliferative disorders with a constitutively active form of the retinoblastoma gene product. Science. 1995;267:518-22.

143. Morishita R, Gibbons GH, Horiuchi M, et al. A gene therapy strategy using a transcription factor decoy of the E2F binding site inhibits smooth muscle proliferation in vivo. Proc Natl Acad Sci USA. 1995;92:5855-9.

144. Kawauchi M, Suzuki J, Morishita R, et al. Gene therapy for attenuating cardiac allograft arteriopathy using ex vivo E2F decoy transfection by HVJ-AVE-liposome method in mice and nonhuman primates. Circ Res. 2000;87:1063-8.

145. Wills KN, Mano T, Avanzini JB, et al. Tissue-specific expression of an anti-proliferative hybrid transgene from the human smooth muscle alpha-actin promoter suppresses smooth muscle cell proliferation and neointima formation. Gene Ther. 2001:8:1847-54.
146. Sinnaeve P, Chiche JD, Gillijns H, et al. Overexpression of a constitutively active protein kinase $G$ mutant reduces neointima formation and in-stent restenosis. Circulation. 2002;105:2911-6.

147. Frimerman A, Welch PJ, Jin X, et al. Chimeric DNA-RNA hammerhead ribozyme to proliferating cell nuclear antigen reduces stent-induced stenosis in a porcine coronary model. Circulation. 1999;99:697-703.

148. Maillard L, Van Belle E, Smith RC, et al. Percutaneous delivery of the gax gene inhibits vessel stenosis in a rabbit model of balloon angioplasty. Cardiovasc Res. 1997;35:536-46.

149. Stephan D, San H, Yang ZY, et al. Inhibition of vascular smooth muscle cell proliferation and intimal hyperplasia by gene transfer of beta-interferon. Mol Med. 1997;3:593-9.

150. Ueno H, Yamamoto H, Ito S, et al. Adenovirus-mediated transfer of a dominant-negative H-ras suppresses neointimal formation in balloon-injured arteries in vivo. Arterioscler Thromb Vasc Biol. 1997;17:898-904.

151. Mano T, Luo Z, Malendowicz SL, et al. Reversal of GATA-6 downregulation promotes smooth muscle differentiation and inhibits intimal hyperplasia in balloon-injured rat carotid artery. Circ Res. 1999;84:647-54.

152. Maillard L, Van Belle E, Tio FO, et al. Effect of percutaneous adeno- virus-mediated Gax gene delivery to the arterial wall in double-injured atheromatous stented rabbit iliac arteries. Gene Ther. 2000;7:1353-61.

153. Lowe HC, Fahmy RG, Kavurma MM, et al. Catalytic oligodeoxynucleotides define a key regulatory role for early growth response factor- 1 in the porcine model of coronary in-stent restenosis. Circ Res. 2001;89:670-7.

154. Tulis DA, Durante W, Liu X, et al. Adenovirus-mediated heme oxygenase-1 gene delivery inhibits injury-induced vascular neointima formation. Circulation. 2001;104:2710-5.

155. Kong D, Melo LG, Mangi AA, et al. Enhanced inhibition of neointimal hyperplasia by genetically engineered endothelial progenitor cells. Circulation. 2004;109:1769-75.

156. Carmeliet $\mathrm{P}$, Moons L, Lijnen R, et al. Inhibitory role of plasminogen activator inhibitor-1 in arterial wound healing and neointima formation: A gene targeting and gene transfer study in mice. Circulation. 1997;96:3180-91.

157. Furman $\mathrm{C}$, Luo $\mathrm{Z}$, Walsh $\mathrm{K}$, et al Systemic tissue inhibitor of metalloproteinase-1 gene delivery reduces neointimal hyperplasia in balloon- injured rat carotid artery. FEBS Lett. 2002;531:122-6.

158. Turunen MP, Puhakka HL, Koponen JK, et al. Peptide-retargeted adenovirus encoding a tissue inhibitor of metalloproteinase-1 decreases restenosis after intravascular gene transfer. Mol Ther. 2002;6:306-12.

159. Turunen P, Puhakka HL, Heikura T, et al. Extracellular superoxide dismutase with vaccinia virus anti-inflammatory protein $35 \mathrm{~K}$ or tissue inhibitor of metalloproteinase-1: Combination gene therapy in the treatment of vein graft stenosis in rabbits. Hum Gene Ther. 2006;17:405-14.

160. Puhakka HL, Turunen P, Gruchala M, et al. Effects of vaccinia virus anti-inflammatory protein $35 \mathrm{~K}$ and TIMP-1 gene transfers on vein graft stenosis in rabbits. In Vivo. 2005;19:515-21.

161. Puhakka HL, Turunen P, Rutanen J, et al. Tissue inhibitor of metalloproteinase 1 adenoviral gene therapy alone is equally effective in reducing restenosis as combination gene therapy in a rabbit restenosis model. J Vasc Res. 2005;42:361-7.

162. Asahara T, Chen D, Tsurumi Y, et al. Accelerated restitution of endothelial integrity and endothelium-dependent function after phVEGF165 gene transfer. Circulation. 1996;94:3291-302

163. Hiltunen MO, Laitinen M, Turunen MP, et al. Intravascular adenovirus-mediated VEGF-C gene transfer reduces neointima formation in balloon-denuded rabbit aorta. Circulation. 2000;102:2262-8.

164. Rade JJ, Schulick AH, Virmani R, et al. Local adenoviral-mediated expression of recombinant hirudin reduces neointima formation after arterial injury. Nat Med. 1996;2:293-8.

165. Zoldhelyi P, Chen ZQ, Shelat HS, et al. Local gene transfer of tissue factor pathway inhibitor regulates intimal hyperplasia in atherosclerotic arteries. Proc Natl Acad Sci U S A. 2001:98:4078-83.

166. Yin X, Yutani C, Ikeda Y, et al. Tissue factor pathway inhibitor gene delivery using HVJ-AVE liposomes markedly reduces restenosis in atherosclerotic arteries. Cardiovasc Res. 2002;56:454-63.

167. Yin X, Fu Y, Yutani C, et al. HVJ-AVE liposome-mediated tissue factor pathway inhibitor (TFPI) gene transfer with recombinant TFPI (rTFPI) irrigation attenuates restenosis in atherosclerotic arteries. Int J Cardiol. 2009;135:245-8.

168. Wu KK. Prostacyclin and nitric oxide-related gene transfer in preventing arterial thrombosis and restenosis. Agents Actions Suppl. 1997;48:107-23.

169. Todaka T, Yokoyama C, Yanamoto H, et al. Gene transfer of human prostacyclin synthase prevents neointimal formation after carotid balloon injury in rats editorial Comment. Stroke. 1999;30:419-26.

170. Shyue SK, Tsai MJ, Liou JY, et al. Selective augmentation of prostacyclin production by combined prostacyclin synthase and cyclooxygenase- 1 gene transfer. Circulation. 2001:103.2090-5.

171. Numaguchi Y, Okumura K, Harada M, et al. Catheter-based prostacyclin synthase gene transfer prevents in-stent restenosis in rabbit atheromatous arteries. Cardiovasc Res. 2004;61:177-85.

172. von der Leyen HE, Gibbons GH, Morishita R, et al. Gene therapy inhibiting neointimal vascular lesion: in vivo transfer of endothelial cell nitric oxide synthase gene. Proc Natl Acad Sci USA. 1995;92:1137-41.

173. Chen L, Daum G, Forough R, et al. Overexpression of human endothelial nitric oxide synthase in rat vascular smooth muscle cells and in balloon-injured carotid artery. Circ Res. 1998;82:862-70. 
174. Janssens S, Flaherty D, Nong Z, et al. Human endothelial nitric oxide synthase gene transfer inhibits vascular smooth muscle cell proliferation and neointima formation after balloon injury in rats. Circulation. 1998;97:1274-81.

175. Shears LL 2nd, Kibbe MR, Murdock AD, et al. Efficient inhibition of intimal hyperplasia by adenovirus-mediated inducible nitric oxide synthase gene transfer to rats and pigs in vivo. J Am Coll Surg. 1998;187:295-306.

176. Varenne O, Pislaru S, Gillijns H, et al. Local adenovirus-mediated transfer of human endothelial nitric oxide synthase reduces luminal narrowing after coronary angioplasty in pigs. Circulation. 1998;98:919-26.

177. Klugherz BD, Jones PL, Cui X, et al. Gene delivery from a DNA controlled-release stent in porcine coronary arteries. Nat Biotechnol. 2000;18:1181-4.

178. Sharif F, Hynes SO, McCullagh KJ, et al. Gene-eluting stents: non-viral, liposome-based gene delivery of eNOS to the blood vessel wall in vivo results in enhanced endothelialization but does not reduce restenosis in a hypercholesterolemic model. Gene Ther. 2012;19:321-8

179. Egashira K, Nakano K, Ohtani K, et al. Local delivery of anti-monocyte chemoattractant protein-1 by gene-eluting stents attenuates in-stent stenosis in rabbits and monkeys. Arterioscler Thromb Vasc Biol. 2007;27:2563-8.

180. Jin X, Mei L, Song C, et al. Immobilization of plasmid DNA on an anti-DNA antibody modified coronary stent for intravascular site-specific gene therapy. J Gene Med. 2008;10:421-9.

181. Perlstein I, Connolly JM, Cui X, et al. DNA delivery from an intravascular stent with a denatured collagen-polylactic-polyglycolic acid-controlled release coating: mechanisms of enhanced transfection. Gene Ther. 2003;10:1420-8.

182. Wang Y, Yu M, Zhang $L$, et al. Immobilization of gene vectors on bisphosphonate-mediated gene-eluting metal stents using antibody for localized gene delivery. J Control Release. 2011;152(Suppl 1):e173-e174.

183. Morishita R, Gibbons GH, Ellison KE, et al. Single intraluminal delivery of antisense cdc2 kinase and proliferating-cell nuclear antigen oligonucleotides results in chronic inhibition of neointimal hyperplasia. Proc Natl Acad Sci U S A. 1993;90:8474-8.

184. Morishita R, Gibbons GH, Ellison KE, et al. Intimal hyperplasia after vascular injury is inhibited by antisense cdk 2 kinase oligonucleotides. J Clin Invest. 1994;93:1458-64.

185. Cohen-Sacks H, Najajreh Y, Tchaikovski V, et al. Novel PDGFbetaR antisense encapsulated in polymeric nanospheres for the treatment of restenosis. Gene Ther. 2002:9:1607-16.

186. Johnson TW, Wu YX, Herdeg C, et al. Stent-based delivery of tissue inhibitor of metalloproteinase-3 adenovirus inhibits neointimal formation in porcine coronary arteries. Arterioscler Thromb Vasc Biol. 2005;25:754-9.

187. Klugherz BD, Song C, DeFelice S, et al. Gene delivery to pig coronary arteries from stents carrying antibody-tethered adenovirus. Hum Gene Ther. 2002;13:443-54.

188. Chorny M, Fishbein I, Alferiev IS, et al. Adenoviral gene vector tethering to nanoparticle surfaces results in receptor-independent cell entry and increased transgene expression. Mol Ther. 2006;14:382-91.

189. Brito LA, Chandrasekhar S, Little SR, et al. Non-viral eNOS gene delivery and transfection with stents for the treatment of restenosis. Biomed Eng Online. 2010;9:56.

190. Takemoto Y, Kawata H, Soeda T, et al. Human placental ectonucleoside triphosphate diphosphohydrolase gene transfer via gelatin-coated stents prevents in-stent thrombosis. Arterioscler Thromb Vasc Biol. 2009;29:857-62.

191. Godin B, Sakamoto JH, Serda RE, et al. Emerging applications of nanomedicine for the diagnosis and treatment of cardiovascular diseases. Trends Pharmacol Sci. 2010;31:199-205.

192. Martinez AW, Chaikof EL. Microfabrication and nanotechnology in stent design. Wiley Interdiscip Rev Nanomed Nanobiotechnol. 2011;3:256-68.

193. Kipshidze NN, Iversen P, Kim HS, et al. Advanced c-myc antisense (AVI-4126)-eluting phosphorylcholine-coated stent implantation is associated with complete vascular healing and reduced neointimal formation in the porcine coronary restenosis model. Catheter Cardiovasc Interv. 2004;61:518-27.

194. Kipshidze N, Iversen P, Overlie P, et al. First human experience with local delivery of novel antisense AVI-4126 with Infiltrator catheter in de novo native and restenotic coronary arteries: 6-month clinical and angiographic follow-up from AVAIL study. Cardiovasc Revasc Med. 2007;8:230-5

195. Jere D, Arote R, Jiang HL, et al. Biodegradable nano-polymeric system for efficient Akt1 siRNA delivery. J Nanosci Nanotechnol. 2010;10:3366-9.

196. Jiang HL, Hong SH, Kim YK, et al. Aerosol delivery of spermine-based poly(amino ester)/Akt1 shRNA complexes for lung cancer gene therapy. Int J Pharm. 2011;420:256-65.

197. Che HL, Bae IH, Lim KS, et al. Suppression of post-angioplasty restenosis with an Akt1 siRNA-embedded coronary stent in a rabbit model. Biomaterials. Biomaterials. 2012;33:8548-56.

198. Kalra M, Jost CJ, Severson SR, et al. Adventitial versus intimal liposome-mediated ex vivo transfection of canine saphenous vein grafts with endothelial nitric oxide synthase gene. J Vasc Surg. 2000;32:1190-200.

199. Lahtinen M, Blomberg P, Baliulis G, et al. In vivo h-VEGF165 gene transfer improves early endothelialisation and patency in synthetic vascular grafts. Eur J Cardiothorac Surg. 2007;31:383-90.

200. Swanson N, Hogrefe K, Javed Q, et al. Vascular endothelial growth factor (VEGF)-eluting stents: in vivo effects on thrombosis, endothelialization and intimal hyperplasia. J Invasive Cardiol. 2003;15:688-92.
201. Paul A, Shao W, Shum-Tim D, et al. The attenuation of restenosis following arterial gene transfer using carbon nanotube coated stent incorporating TAT/DNA(Ang1+Vegf) nanoparticles. Biomaterials. 2012;33:7655-64.

202. Yang J, Zeng Y, Zhang C, et al. The prevention of restenosis in vivo with a VEGF gene and paclitaxel co-eluting stent. Biomaterials. 2013;34:1635-43.

203. Lemos PA, Farooq V, Takimura CK, et al. Emerging technologies: polymer-free phospholipid encapsulated sirolimus nanocarriers for the controlled release of drug from a stent-plus-balloon or a stand-alone balloon catheter. EuroIntervention. 2013;9:148-56. 